Academic Platform Journal of Engineering and Science

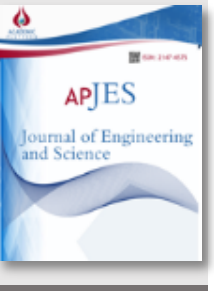

\title{
Makine Öğrenimi Yöntemleri ile Türkiye için Sera Gazı Emisyonu Tahmini
}

\author{
${ }^{* 1}$ Melike Şişeci Çeşmeli, ${ }^{2}$ İhsan Pençe \\ ${ }^{1}$ Burdur Mehmet Akif Ersoy Üniversitesi, melikesiseci@mehmetakif.edu.tr, \\ ${ }^{2}$ Burdur Mehmet Akif Ersoy Üniversitesi, ihsanpence@mehmetakif.edu.tr, \\ Araştırma Makalesi \\ Geliş Tarihi: 13.12.2019 \\ Kabul Tarihi: 26.03.2020
}

$\ddot{O} \mathbf{z}$

Sera gazı emisyonu dünyamızın kendini yenileme kapasitesinin önüne geçerek, ozon tabakasının delinmesi, küresel ısınma ve besin kaynaklarının azalması gibi sonuçlara sebep olmaktadır. Ayrıca sera gazları, ekolojik ayak izini oluşturan en büyük etmendir. Dünyanın daha yaşanılabilir ve kendi kendine yetebilir olması için biyokütle alanları ile ekolojik ayak izi dengede olmalıdır. Bu dengeyi sağlamak için ise sera gazı emisyonunun ileriye yönelik durumu belirlenmelidir. Bu çalışmada, makine öğrenimi algoritmaları kullanılarak Türkiye için ileriye yönelik sera gazı emisyonu tahminlemesi gerçekleştirilmiş olup, veri setini Türkiye'ye ait 1967-2017 yılları arasındaki sera gazı emisyonu oluşturmaktadır. Yöntemlerin başarısını sınamak için öncelikle veri seti zaman serisi olarak ele alınmış daha sonra ise istatistiksel olarak da sonuçları değerlendirmek için 10-kat çapraz doğrulama uygulanmıştır. En iyi algoritma olarak Uzun Kısa-Vadeli Hafiza tespit edilmiş olup zaman serisi olarak değerlendirilen test setinde bu algoritmanın ortalama karesel hataların karekökü, ortalama mutlak yüzde hata ve belirleme katsayısı değerleri sırası ile 0.25, 1.11, 1.0 bulunmuştur. Bu başarılı sonuçlar ile oluşturulan model 2018-2031 yılına kadar olan sera gazı emisyonunu tahmin etmek için kullanılmıştır. Tahmin edilen emisyon değerleri günümüze göre yüksek seviyede olup bu değerler göz önüne alınarak gerekli tedbir ve biyokütleyi artırıcı faaliyetlerin gerçekleştirilmesi gerekmektedir.

Anahtar Kelimeler: Sera gazı emisyonu, Makine öğrenimi, Derin Öğrenme, Uzun Kısa-Vadeli Hafıza, Tahminleme.

\section{Forecasting of Greenhouse Gas Emissions in Turkey using Machine Learning Methods}

\author{
*11Melike Şişeci Çeşmeli, ${ }^{2}$ İhsan Pençe \\ ${ }^{1}$ Burdur Mehmet Akif Ersoy University, melikesiseci@mehmetakif.edu.tr \\ ${ }^{2}$ Burdur Mehmet Akif Ersoy University, ihsanpence@mehmetakif.edu.tr
}

\begin{abstract}
Greenhouse gas emissions prevent our world's self-renewal capacity and cause ozone depletion, global warming and reduced food resources. In addition, greenhouse gases are the biggest factor that creates the ecological footprint. To make the world more livable and self-sufficient, the biocapacity fields and the ecological footprint must be in balance. In order to achieve this balance, the situation for the future of greenhouse gas emissions should be determined. In this study, the forecasting of greenhouse gas emissions for Turkey is carried out using machine learning algorithms, and the data set denominated greenhouse gas emissions of Turkey between the years 1967-2017. In order to test the success of the methods, the data set is first handled as a time series and then 10-fold cross-validation is applied to evaluate the results statistically. Long Short-Term Memory is determined as the best algorithm and in the test set evaluated as time series, root mean square error, mean absolute percentage error and the coefficient of determination of this algorithm are found as $0.25,1.11$, and 1.0 respectively. The model created with these successful results is used to estimate greenhouse gas emissions between 2018 and 2031. Forecasted emission values are at a high level compared to today, and necessary measures and activities to increase biomass should be carried out considering these values.
\end{abstract}

Keywords: Greenhouse gas emissions, Machine learning, Deep Learning, Long Short-Term Memory, Forecasting. 


\section{GÍRIŞ̧}

Karbon gazının da büyük çoğunluğunu oluşturduğu sera gazı emisyonu, son yıllarda dünyamızın kendini yenileme kapasitesinin önüne geçmektedir. Özellikle Sanayi Devrimi'nden sonra büyük ölçüde fosil yakıtlara dayanan enerji üretimi, küresel 1sınmaya yol açan sera gazı emisyonlarında hızlı bir artışa neden olmuştur. $\mathrm{Bu}$ durum ozon tabakasının delinmesi, küresel 1sınma, besin kaynaklarının azalması ve iklim değişikliği gibi sonuçlara sebep olmaktadır. Değişen iklimin ise çeşitli ekolojik, fiziksel ve sağlık etkileri bulunmaktadır. Bunlar arasında aşırı depresif hava olayları, iklimde kar örtüsü, deniz buzu ve buz tabakalarının hacminde azalma, deniz seviyesinde yükselme, değişmiş ürün büyümesi ve bozulmuş su sistemleri bulunmaktadır [1], [2]. En büyük oranını sera gazlarının oluşturduğu ve insan tüketimlerine bağlı olan ekolojik ayak izi ise, daha yaşanılabilir ve kendi kendine yetebilen bir dünya için biyokütle alanları ile dengede olmalıdır. Fakat son yıllarda sera gazı emisyonu gitgide artmakta olup, alınacak önemler için emisyon miktarının ileriye yönelik belirlenmesi gerekmektedir.

Sera gazı emisyonunun etkisi ile atmosferde oluşan olumsuz değişikliklere bağlı olarak dünyamızın ortalama sıcaklığı gittikçe artmaktadır [3]. Dünyamızın ortalama sıcaklığı 1850 ile 2018 yılları arasında ortalama $1.2^{\circ} \mathrm{C}$ değişime uğrarken, 1961 ile 1990 yılları ise ortalama sıcaklık değişiminin en fazla yaşandığ 1 dönemdir [1], [3]. Küresel 1sınmanın nedenlerini hafifletici önlemlerin alınması da yine konu ile ilgili araştırılma ve gelecek tahminlerini gerektirmektedir [2]. Şekil 1'de yıllara göre dünyanın ortalama sıcaklığındaki değişimler görülmektedir.

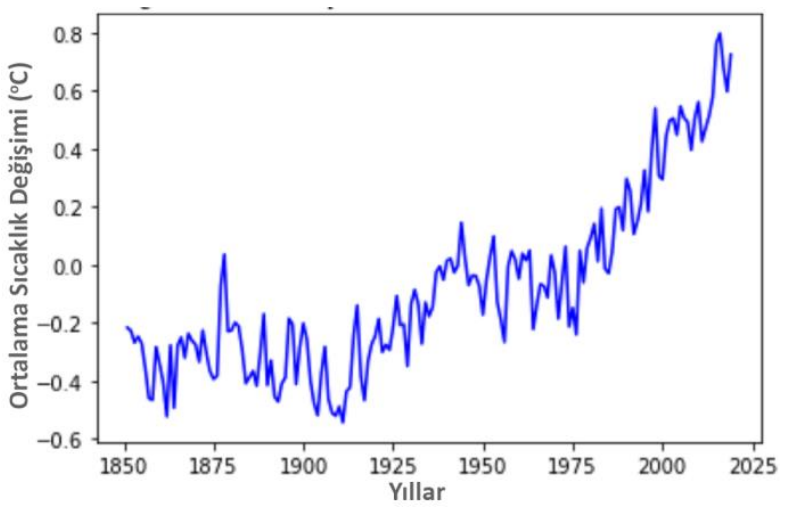

Şekil 1. 1850-2018 yılları arasında dünyanın ortalama sıcaklığındaki değişimler [2]

1900 yılında 2 milyar ton olan karbon emisyonu 2017 yılında 36 milyar ton olmuş olup bu artış oranı dünyamızın yaşanabilir bir yer olmasını tehdit etmektedir. Toprak organik karbon (C) tutunma potansiyeli ve toprak azot oksit $\left(\mathrm{N}_{2} \mathrm{O}\right)$ emisyonları açısından toprak türlerindeki farklılıklar da sera gazı emisyonları üzerinde etkili olup bu sebeple bölgelerin veya ülkelerin kendi içlerinde de analiz edilmesi önemlidir. Mevcut botanik bileşim, çevresel koşullara göre otlatma zamanlamasının yanı sıra emme ve besin değerini de etkileyebilmektedir [4]. Şekil 2'de dünyadaki bölgelere göre karbon emisyonu ton cinsinden görülmektedir.

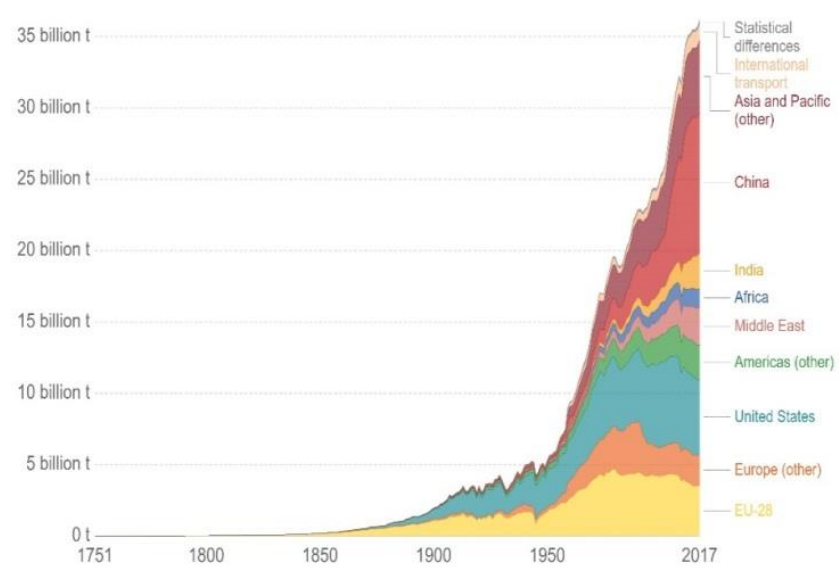

Şekil 2. Bölgelere göre karbon emisyonu [1]

Sera gazı emisyonunda hangi gazların ne kadar bulundukları ton cinsinden Şekil 3 'te görülmektedir.

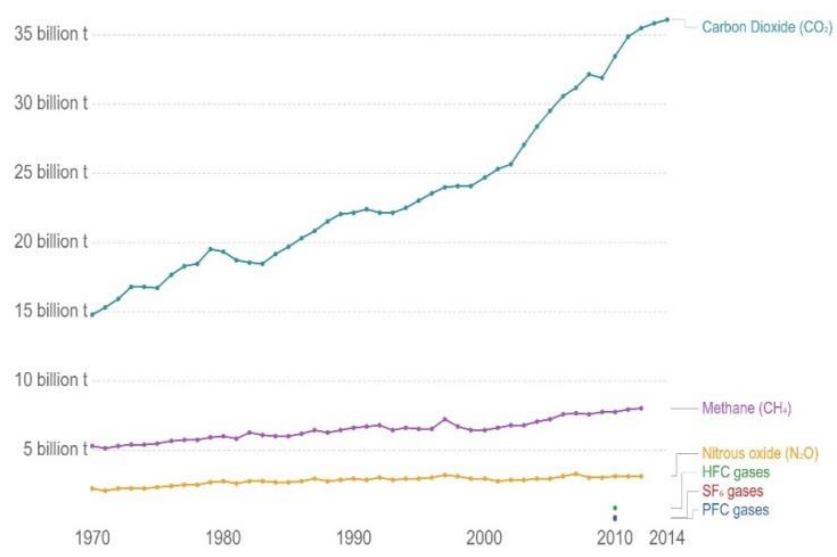

Şekil 3. Gaz çeşidine göre sera gazı emisyonu değerleri [1]

Şekil 3'te de görüldüğü gibi sera gazı emisyonuna etki eden gazların büyük çoğunluğunu $\mathrm{CO}_{2}$ oluşturmasına rağmen diğer gazların etkisi de azımsanmayacak seviyededir. Fakat yıllara göre değişim miktarı en çok olan gaz çeşidi de yine $\mathrm{CO}_{2}$ dir [5]. Bu sebeple, dünyamızın üretebildiği biyokütle miktarından gittikçe artarak aradaki farkı açan ekolojik ayak izi oranını kontrol altına alabilmek için sera gazı veya $\mathrm{CO}_{2}$ emisyonunun tespiti oldukça önemlidir. İleriye yönelik sera gazı emisyonu tahmini, ülkelerin ve üzerinde yaşadığımız dünyamızın daha yaşanabilir bir yer olması için yol gösterici olacaktır. Tahminleme, günümüzde birçok alanda kullanılmakta olup yapay zekâ ve makine öğrenimi algoritmaları ile gerçekleştirilebilmektedir.

Sera gazı emisyonu üzerine yapılan literatür çalışmaları incelendiğinde, ilk olarak yapay zekâ teknikleri kullanılarak modelleme ve tahminleme işlemlerinin yapıldığ 1 çalışmalar göze çarpmaktadır. Bunlardan bazıları üretim tesislerinin veya üretilen ürünlerin sera gazı emisyonunun modellenmesinin ve tahminlerinin yapıldığı çalışmalardır 
[6], [7], [8], [9], [10], [11], [12], [13], [14]. Literatürdeki benzer diğer çalışmalar ise; en büyük sera gazı emisyonu olan $\mathrm{CO}_{2}$ çözünürlüğ̈n̈ün Yapay Sinir Ağları (YSA) ile tahminlenmesi [15], yine YSA ile sera gazının modellenmesi [16], sera gazı emisyonunu azaltmak için veri madenciliği teknikleri ile yeni ulaştırma sistemleri önermesi [17], portakal tarımı için enerjinin ve sera gazının YSA ve genetik algoritma ile optimize edildiği çalışma [18], sera gazı ve hava kirliliğini azaltma stratejileri için iş zekâsı modelinin önerildiği yada $\mathrm{CO}_{2}$ emisyonunu azaltmak için akıllı teknoloji çalışmaları [19], [20], bölgesel ve küresel düzeyde emisyon ve maliyet azaltmak için GAINS bulut akıllı servis sistemi [21], arl kolonisi ve YSA ile karbondioksit emisyon tahmini çalışması [22], çeltik üretiminin veya besi çiftliklerinin enerji çıktısı ve çevresel etkilerinin tahmini için yapay zekâ tekniklerinin kullanıldığı [23], [24] çalışmalar göze çarpmaktadır.

Toprak türlerindeki farklılıkların sera gazı emisyonları üzerinde etkili olduğu bilinmekte olup [4], ülkelerin bu açıdan kendi içinde değerlendirilmeleri önemlidir. $\mathrm{Bu}$ sebeple gerçekleş̧irilen bu çalışma, literatürde Türkiye'nin sera gazı emisyonu üzerine olan literatürü güçlendirecektir. Ayrıca derin öğrenme tabanlı algoritmaların sera gazı emisyonlarının modellenmesinde literatürdeki çalışmaların eksikliği görülmekte olup derin öğrenme algoritmaları arasında yer alan Uzun Kisa-Vadeli Hafiza (LSTM) yönteminin zaman serisi problemleri ve sera gazı emisyon modellemelerinde başarılı sonuçlar verdiği de yine yapılan çalışma ile gösterilmiştir.

Türkiye için ileriye yönelik sera gazı emisyonu tahminlemesinin gerçekleştirildiği çalışmada, makine öğrenimi algoritmalarından Poisson regresyonu, lineer regresyon (LR), YSA, Adaptif Ağ Tabanlı Bulanık Çıkarım Sistemi (ANFIS) ve LSTM kullanılmış olup veri setini Türkiye'ye ait 1967-2017 yılları arasındaki milyar ton cinsinden sera gazı emisyonu oluşturmaktadır. Yararlanılan algoritmalar literatürdeki popülerlikleri sebebiyle tercih edilmiş olup, derin öğrenme yöntemleri arasında yer alan ve özelikle de zaman serisi problemleri için kullanılan LSTM de güncel ve popüler algoritmalar arasindadır.

\section{MATERYAL VE METOT}

$\mathrm{Bu}$ çalışmada modellemesi ve tahmini gerçekleştirilen Türkiye'ye ait sera gazı emisyonu için yararlanılan veri seti Ritchie, H. ve Roser, M.'nin derlediği verilerden oluşmaktadır [1]. Veri seti, 1750-2019 yılları arasında farklı ülkelerin sera gazı emisyonlarını içermekte olup, bu çalışmada Türkiye'ye ait var olan son veriye ait 2017 yılı baz alınarak son 50 yılı içeren 1967-2017 yıllarına ait değerler kullanılmıştır. Ton cinsinden yer alan sera gazı emisyonları hesaplama kolaylığı açısından milyar tona çevrilerek kullanılmıştır. Algoritmaların özniteliklerini tarih bilgisi oluşturmakta olup, çıkış değerlerini ise milyar ton cinsinden sera gazı miktarı oluşturmaktadır. Veri setine ait bazı örnekler Tablo 1'de yer almaktadır.
Tablo 1. Türkiye'ye ait sera gazı emisyon miktarları

\begin{tabular}{|c|c|}
\multicolumn{1}{c}{ (Milyar Ton) } \\
\hline Tarih & Sera Gaz1 Emisyonu \\
\hline 1967 & 0.505138 \\
\hline 1968 & 0.541404 \\
\hline 1969 & 0.580156 \\
\hline$\cdot$ & $\cdot$ \\
$\cdot$ & $\cdot$ \\
$\cdot$ & $\cdot$ \\
\hline 2015 & 8.751768 \\
\hline 2016 & 9.154589 \\
\hline 2017 & 9.602486 \\
\hline
\end{tabular}

Sera gazı emisyonu için oluşturulacak makine öğrenimi modeli öznitelik olarak yıl bilgisini kullanmakta olup zaman serisi biçimindedir. Bu sebeple veri seti zaman serisi şeklinde ele alınıp test edilmiştir. Bunun yanında modelin kendi içerisinde de iyi kurulduğunu tespit etmek için istatistiksel bir yöntem olan çapraz doğrulamadan da yararlanılmıştır. Çapraz doğrulama, öğrenen modelin daha önce görmediği veriler için yeni tahminler yapması istenildiğinde ne kadar iyi tahmin yapabileceğinin bir göstergesi olabilen istatistiksel bir model değerlendirme yöntemidir. Elde edilen en başarılı model daha sonra ileriye yönelik sera gazı emisyonunu tahmin etmek için kullanılmıştır. Makine öğrenimi algoritmalarından Poisson regresyonu, LR, YSA, ANFIS ve LSTM'nin kullanıldığı çalışmada zaman serisi ve çapraz doğrulama testlerinde en iyi sonucu veren algoritma belirlenirken, algoritmalara ait en uygun parametrelere ise grid arama sonucunda karar verilmiştir. Grid arama, belirtilen her hiperparametre kombinasyonu için bir model oluşturur ve her bir modeli ayrı ayrı değerlendirir [25]. Normalizasyonun modelin eğitimine ilişkin etkisi de incelenmiş olup bunun için min-max normalizasyonu kullanılmıştır. Bu normalizasyon tekniği veriyi doğrusal olarak Eşitlik (1)'deki gibi [0-1] aralığında normalleştirir.

$x_{i}^{\prime}=\frac{\left(x_{i}-x_{\min }\right)}{x_{\max }-x_{\min }}$

Eşitlik (1)'de $x_{i}$ normalize edilecek $i$. veriyi, $x_{i}^{\prime}$ normalize edilmiş veriyi, $x_{\min }$ ve $x_{\max }$ ise veri setindeki minimum ve maksimum değerleri ifade etmektedir.

Modellerin başarılarını değerlendirmek için ise Ortalama Karesel Hataların Karekökü (RMSE), Ortalama mutlak Yüzde Hata (MAPE) ve belirleme katsayıs $\left(\mathrm{R}^{2}\right)$ kullanılmıştır.

Eşitlik (2)'de RMSE, Eşitlik (3)'te MAPE ve Eşitlik (4)'te ise $\mathrm{R}^{2}$ formülleri verilmiştir.

$R M S E=\sqrt{\frac{1}{n} \sum_{i=1}^{n}\left(y_{i}-\hat{y}_{i}\right)^{2}}$

Eşitlik (2)'de $y$ hedeflenen emisyon değerini, $\hat{y}$ ise bulunan emisyon değerini ifade etmekte olup, $n$ ise örnek sayısıdır. 
$M A P E=\left(\frac{1}{n} \sum_{i=1}^{n} \frac{\left|y_{i}-\widehat{y_{l}}\right|}{\left|y_{i}\right|}\right) * 100$

Eşitlik (3)'te MAPE formülü verilmiş olup $y$ hedeflenen emisyon değerini, $\hat{y}$ ise bulunan emisyon değerini, $n$ ise örnek sayısını ifade etmektedir. MAPE, hatanın boyutunu yüzde olarak ölçmektedir.

$R^{2}=1-\frac{\sum_{i=1}^{n}\left(y_{i}-\widehat{y_{l}}\right)^{2}}{\sum_{i=1}^{n}\left(y_{i}-\bar{y}_{i}\right)^{2}}$

Eşitlik (4)'te $y$ hedeflenen emisyon değerini, $\hat{y}$ bulunan emisyon değerini, $\bar{y}$ hedeflenen emisyon değerinin ortalamasını, $n$ ise örnek sayısını ifade etmektedir.

Sonuçların değerlendirilmesi için ayrıca Wilcoxon rank sum testte uygulanmış olup, null test iki dağılımdaki verilerin eşit medyanlarla sürekli dağılımlardan alınan örnekler olduğunu belirtmektedir.

$\mathrm{Bu}$ çalışmada makine öğrenimi algoritmalarını çalıştırmak için Pycharm JetBrains PyCharm Community Edition 2019.3 programı kullanılmıştır.

\subsection{Poisson Regresyonu}

Poisson regresyonu, normal çoklu regresyona benzemekle birlikte burada bağımlı değişken Poisson dağılımını izleyen 0, 1, 2, 3 gibi gözlenen bir sayı olmaktadır. Poisson regresyonu, ayrık yanıt değişkenine sahip olan lojistik regresyona benzemekte olup, yanit lojistik regresyonda olduğu gibi belirli değerlerle sinırlı değildir. Poisson dağılımı, bağımlı değişkene ilişkin olayların gerçekleşme olasılığını matematiksel bir eşitlik ile modellemektedir. Nadir görülen bir olayın ortalama görülme oranı maruz kalma birimi ile ifade edilmekte olup, ilgili maruz kalma zaman, mekân, mesafe, alan, hacim veya popülasyon büyüklügü olabilmektedir. Maruz kalma genellikle bir süre olduğu için $t$ ile ifade edilmektedir. Bağımlı değişkene ait olayların olasılığı Eşitlik (5) ile ifade edilebilir [26].

$\operatorname{Pr}(Y=y \mid \mu, t)=\frac{e^{-\mu t}(\mu t)^{y}}{y !}(y=0,1,2, \ldots)$

Eşitlik (5)'te $y$ bağımlı değişkeni ifade ederken, $\mu$ parametresi ise belirli bir $t$ periyodu kadar maruz kalma süresi boyunca olayın yeni bir oluşum riski olarak yorumlanabilmektedir. Poisson dağılımı ortalama ve varyansın eşit olması özelliğine sahiptir [27].

\subsection{Lineer Regresyon}

LR, iki veya daha fazla değişken arasındaki ilişkiyi bir fonksiyon ile elde etmektedir. Bu ilişkinin düzeyi regresyon analizi ile ölçülebilmektedir. LR ile oluşturulan fonksiyon lineer olup Eşitlik (6)'daki gibidir. $y=a x+b$

Eşitlik (6)'da $x$ öznitelikleri, $y$ ise çıktı değerlerini ifade etmekte olup, verilere en iyi uyan doğru çizgisi, her bir veri noktası için hatanın en küçük olanıdır. Bunu sağlamak için ise en çok kullanılan yöntem en küçük kareler metodudur.

\subsection{Yapay Sinir A Ağları}

YSA, insan beyninin çalışma şeklinin modellenmesiyle oluşturulmuş ve eğitilip öğrenmeyi gerçekleştiren sinir hücrelerini kullanmaktadır. Sinir hücresi olan nöronlar birbirleri ile bir ağ şeklinde bağlanırlar. YSA ağ tipine bağlı olarak genellikle ileri beslemeli, çok katmanlı ve geri beslemeli olarak ayrılmaktadır. İleri beslemeli sinir ă̆ yapısında nöronlar katmanlar şeklinde düzenlenir ve bir katmandaki nöronların çıkışları yalnızca bir sonraki katmana ağırlıklar üzerinden giriş olarak verilebilmektedir. Verilerin sahip oldukları girdiler giriş katmanında yer alırken, sonuç değerlerine ait çıkışlar da çıkış katmanında bulunmaktadır. Giriş ve çıkış katmanlarının arasında gizli katmanlar bulunur. YSA regresyonu için çıkış katmanında tek bir çıkış bulunmaktadır. Eşitlik (7)'de ileri beslemeli bir ağda tek bir nörona ait çıkış verilmiştir [28].

$a_{i}=f\left(\sum w_{i j} g_{j}+b_{i}\right)$

Eşitlik (7)'de $a_{i}$ ilgili nöronun çıkışını, $w_{i j}$ ağırlıkları, $g_{j}$ girişleri, $b_{i}$ biyas terimini ve $f$ aktivasyon fonksiyonudur.

\subsection{Adaptif Ăg Tabanlı Bulanık Çıkarım Sistemi}

ANFIS, bulanık mantığa ait çıkarım özellikleri ile YSA'nın öğrenme ve paralel hesaplama özelliklerini birlikte çalıştırabilen bir yapay zekâ tekniğidir. Adaptif ağlar, birbirine bağlı düğümlerden oluşup bunlar bir işlem birimine karşılık gelir. Adaptasyon, bu düğümlerin çıkışlarındaki değişebilen parametrelerle belirlenmesi ile oluşturulmaktadır. Öğrenme kuralları, hatayı minimum yapacak şekilde değiştirir [29].

\subsection{Uzun Kısa-Vadeli Hafiza}

LSTM sinir ağı, yinelemeli sinir ağı modeli üzerine geliştirilmiş olup yinelemeli sinir ağının eğitiminde yetersiz kalınmasının üstesinden gelinmesi için önerilmiştir. LSTM zaman bağımlılıkları içermekte olup zaman serisi problemlerinde başarılı sonuçlar vermektedir. LSTM sinir ağının nöron yapısı içerisinde giriş, unutma ve çıkış kapıları bulunmaktadır. Bu sayede, tüm veriler üzerinde zamanda bağımlılık engellenmiş ve belirli iterasyon sonrasında ağın eski bilgileri unutması ve yeni bilgilerle sonuç üretmesi sağlanmıştır [30]. Bir LSTM hücresi Şekil 4'te görülmektedir. 


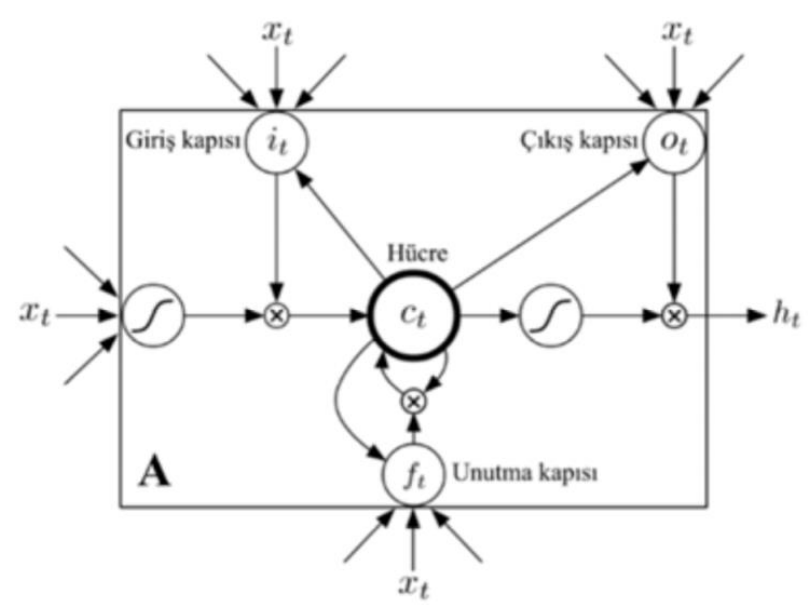

Şekil 4. LSTM hücresi [31]

\section{DENEYSEL ÇALIŞMALAR}

$\mathrm{Bu}$ çalışmada, Türkiye'nin ileriye yönelik sera gazı emisyonu tahminlemesi için Poisson regresyonu, LR, YSA, ANFIS ve LSTM kullanılmış olup modellerin başarıları zaman serisi ve 10-kat çapraz doğrulama ile test edilmiştir. Sera gazı emisyonu zamanla değişim gösterip zaman bağımlıdır dolayısıyla zaman serisi olarak değerlendirilmelidir. Bunun için 1967-2017 yılları arasını kapsayan veri setinin \%70 lik (1967-2001) kısmı eğitim ve \%30'luk (2002-2017) kismı ise test olarak değerlendirilmiştir. Bunun yanında veri setinin kendi içerisinde istatistiksel olarak da başarısını değerlendirmek için 10-kat çapraz doğrulama sonuçları da incelenmiştir.
Makine öğrenimi algoritmaları yararlandıkları parametrelere göre farklı başarı oranları sergileyebilmektedir [32]. Dolayısıyla öncelikle en uygun parametrelerin tespit edilmesi gerekmektedir. En uygun parametrelerin tespiti için grid aramadan yararlanılmıştır. Grid arama yönteminde parametre olarak; YSA için birinci gizli katmanda [50-4030-20-10-5], ikinci gizli katmanda [10-5] ve öğrenme oranı olarak da [0.005-0.05-0.5], ANFIS için kural sayısı olarak [2-3-4-5-7-11-15-19] ve LSTM için ise nöron sayısı olarak [50-45-40-35-30-25-20-15-10-5] ve öğrenme oranı olarak da [0.005-0.05-0.5] değerleri kullanılmıştır. Bu algoritmalar için ortak olarak iterasyon sayısı 1000 olarak belirlenmiştir. YSA ve LSTM algoritmaları için öğrenme yöntemi olarak Adam optimizasyonundan yararlanılmıştır [33]. Diğer yöntemlerden olan LR ve Poisson regresyonu için ise herhangi bir parametreden yararlanılmayip emisyon değerlerinin lineer ya da Poisson dağılımı gösterip göstermedikleri de bu yöntemler sayesinde tespit edilebilmiştir. Oluşturulan modellere normalizasyonun etkisinin incelenebilmesi için tüm yöntemler hem standart şekilde hem de min-max normalizasyonu uygulanıp 30 bağımsız çalışma sonucunda değerlendirilmiştir. Algoritmaların başarıları ölçmek için RMSE, MAPE ve $\mathrm{R}^{2}$ kullanılmış olup istatistiksel bir test olan Wilcoxon Rank Sum testinden de tahminler ile gerçek değerleri karşılaştırmak için yararlanılmıştır. YSA'ya ait elde edilen zaman serisi şeklinde test seti sonuçları Tablo 2'de görülmektedir.

Tablo 2. Zaman serisi biçiminde test seti için YSA yöntemine ait farklı parametreler ile elde edilen sonuçlar

\begin{tabular}{|c|c|c|c|c|c|c|c|c|}
\hline \multicolumn{4}{|c|}{ Parametreler } & \multirow{2}{*}{ RMSE } & \multirow{2}{*}{ MAPE } & \multirow{2}{*}{$\mathrm{R}^{2}$} & \multicolumn{2}{|c|}{ Wilcoxon Rank } \\
\hline $\mathrm{G}_{1}$ & $\mathrm{G}_{2}$ & Öo & Norm. & & & & $h$ & $p$ \\
\hline \multirow{12}{*}{50} & \multirow{6}{*}{10} & \multirow{2}{*}{0.005} & + & $2.28 \pm 0.14$ & 24.32 & -0.85 & - & $7.43 \mathrm{e}-4$ \\
\hline & & & - & $5.68 \pm 3.19$ & 19.11 & $-1 e-3$ & + & 1 \\
\hline & & \multirow{2}{*}{0.05} & + & $2.40 \pm 0.26$ & 22.10 & -0.53 & - & $2.41 \mathrm{e}-3$ \\
\hline & & & - & $5.07 \pm 0.57$ & 48.10 & -5.35 & - & $1.54 \mathrm{e}-6$ \\
\hline & & \multirow{2}{*}{0.5} & + & $2.27 \pm 0.20$ & 20.69 & -0.44 & - & $3.09 \mathrm{e}-3$ \\
\hline & & & - & $7.30 \pm 9.55$ & 21.33 & -0.03 & + & 0.56 \\
\hline & \multirow{6}{*}{5} & \multirow{2}{*}{0.005} & + & $2.38 \pm 0.13$ & 24.57 & -0.88 & - & $4.90 \mathrm{e}-4$ \\
\hline & & & - & $7.04 \pm 3.52$ & 22.09 & -0.08 & + & 0.24 \\
\hline & & \multirow{2}{*}{0.05} & + & $2.33 \pm 0.27$ & 21.14 & -0.47 & - & $2.73 \mathrm{e}-3$ \\
\hline & & & - & $5.22 \pm 0.54$ & 50.84 & -5.92 & - & $1.54 \mathrm{e}-6$ \\
\hline & & \multirow{2}{*}{0.5} & + & $2.37 \pm 0.32$ & 20.83 & -0.46 & - & $2.73 \mathrm{e}-3$ \\
\hline & & & - & $7.95 \pm 9.92$ & 24.32 & -1.47 & - & $3.19 \mathrm{e}-4$ \\
\hline \multirow{11}{*}{40} & \multirow{6}{*}{10} & \multirow{2}{*}{0.005} & + & $2.35 \pm 0.15$ & 23.61 & -0.78 & - & $9.75 \mathrm{e}-4$ \\
\hline & & & - & $5.96 \pm 3.00$ & 18.66 & -0.13 & + & 0.44 \\
\hline & & \multirow{2}{*}{0.05} & + & $2.29 \pm 0.31$ & 17.98 & -0.16 & - & 0.01 \\
\hline & & & - & $5.25 \pm 0.75$ & 26.79 & -1.85 & - & $2.64 \mathrm{e}-5$ \\
\hline & & \multirow{2}{*}{0.5} & + & $2.30 \pm 0.29$ & 18.76 & -0.28 & - & $7.04 \mathrm{e}-3$ \\
\hline & & & - & $6.42 \pm 2.38$ & 23.29 & -0.18 & + & 0.24 \\
\hline & \multirow{5}{*}{5} & \multirow{2}{*}{0.005} & + & $2.34 \pm 0.14$ & 24.39 & -0.86 & - & $6.48 \mathrm{e}-4$ \\
\hline & & & - & $5.20 \pm 1.84$ & 26.57 & -1.83 & - & $2.64 \mathrm{e}-5$ \\
\hline & & \multirow{2}{*}{0.05} & + & $2.35 \pm 0.32$ & 16.81 & -0.09 & - & 0.02 \\
\hline & & & - & $5.17 \pm 0.48$ & 53.67 & -6.54 & - & $1.54 \mathrm{e}-6$ \\
\hline & & 0.5 & + & $2.32 \pm 0.32$ & 18.89 & -0.27 & - & $7.04 \mathrm{e}-3$ \\
\hline
\end{tabular}




\begin{tabular}{|c|c|c|c|c|c|c|c|c|}
\hline & & & - & $5.41 \pm 2.38$ & 23.60 & -1.36 & - & $3.19 \mathrm{e}-4$ \\
\hline \multirow{12}{*}{30} & \multirow{6}{*}{10} & \multirow{2}{*}{0.005} & + & $2.29 \pm 0.15$ & 21.19 & -0.51 & - & 0.002 \\
\hline & & & - & $6.20 \pm 3.68$ & 19.56 & 0.02 & + & 1 \\
\hline & & \multirow{2}{*}{0.05} & + & $2.28 \pm 0.31$ & 19.25 & -0.31 & - & $6.29 \mathrm{e}-3$ \\
\hline & & & - & $5.11 \pm 0.48$ & 52.18 & -6.21 & - & $1.54 \mathrm{e}-6$ \\
\hline & & \multirow{2}{*}{0.5} & + & $2.40 \pm 0.23$ & 22.42 & -0.62 & - & $1.88 \mathrm{e}-3$ \\
\hline & & & - & $11.34 \pm 21.69$ & 47.86 & -5.32 & - & $1.46 \mathrm{e}-6$ \\
\hline & \multirow{6}{*}{5} & \multirow{2}{*}{0.005} & + & $2.31 \pm 0.12$ & 24.87 & -0.90 & - & $4.90 \mathrm{e}-4$ \\
\hline & & & - & $5.13 \pm 2.55$ & 18.95 & -0.02 & + & 0.64 \\
\hline & & \multirow{2}{*}{0.05} & + & $2.38 \pm 0.30$ & 22.06 & -0.62 & - & $2.13 e-3$ \\
\hline & & & - & $5.11 \pm 0.43$ & 51.11 & -5.98 & - & $1.54 \mathrm{e}-6$ \\
\hline & & \multirow{2}{*}{0.5} & + & $2.31 \pm 0.35$ & 16.92 & -0.09 & - & 0.02 \\
\hline & & & - & $10.69 \pm 24.68$ & 46.59 & -5.04 & - & $1.54 \mathrm{e}-6$ \\
\hline \multirow{12}{*}{20} & \multirow{6}{*}{10} & \multirow{2}{*}{0.005} & + & $2.35 \pm 0.17$ & 23.56 & -0.76 & - & $9.75 \mathrm{e}-4$ \\
\hline & & & - & $5.01 \pm 1.18$ & 26.14 & -1.76 & - & $3.68 \mathrm{e}-5$ \\
\hline & & \multirow{2}{*}{0.05} & + & $2.34 \pm 0.29$ & 17.76 & -0.18 & - & 0.01 \\
\hline & & & - & $5.16 \pm 0.51$ & 45.98 & -4.93 & - & $1.54 \mathrm{e}-6$ \\
\hline & & \multirow{2}{*}{0.5} & + & $2.34 \pm 0.25$ & 19.77 & -0.37 & - & $5.60 \mathrm{e}-3$ \\
\hline & & & - & $8.34 \pm 13.54$ & 19.27 & -0.02 & + & 1 \\
\hline & \multirow{6}{*}{5} & \multirow{2}{*}{0.005} & + & $2.33 \pm 0.13$ & 25.20 & -0.94 & - & 0.00 \\
\hline & & & - & $5.34 \pm 2.20$ & 19.00 & -0.01 & + & 0.90 \\
\hline & & \multirow{2}{*}{0.05} & + & $2.35 \pm 0.24$ & 22.90 & -0.68 & - & $1.11 \mathrm{e}-3$ \\
\hline & & & - & $5.22 \pm 0.71$ & 39.14 & -3.69 & - & $1.54 \mathrm{e}-6$ \\
\hline & & \multirow{2}{*}{0.5} & + & $2.38 \pm 0.35$ & 20.31 & -0.43 & - & $4.43 e-3$ \\
\hline & & & - & $5.28 \pm 0.95$ & 42.88 & -4.34 & - & $1.54 \mathrm{e}-6$ \\
\hline \multirow{12}{*}{10} & \multirow{6}{*}{10} & 0005 & + & $2.30 \pm 0.14$ & 24.10 & -0.82 & - & $9.75 \mathrm{e}-4$ \\
\hline & & 0.005 & - & $5.77 \pm 2.20$ & 18.67 & -0.14 & + & 0.28 \\
\hline & & 005 & + & $2.33 \pm 0.24$ & 20.55 & -0.41 & - & $3.94 \mathrm{e}-3$ \\
\hline & & 0.05 & - & $5.09 \pm 0.68$ & 45.57 & -4.85 & - & $1.54 \mathrm{e}-6$ \\
\hline & & 05 & + & $2.32 \pm 0.43$ & 13.86 & 0.16 & + & 0.06 \\
\hline & & 0.5 & - & $6.41 \pm 3.54$ & 23.14 & -1.27 & - & $2.73 e-3$ \\
\hline & & 0005 & + & $2.33 \pm 0.11$ & 23.79 & -0.78 & - & $9.75 \mathrm{e}-4$ \\
\hline & & 0.005 & - & $4.88 \pm 1.22$ & 25.22 & -1.62 & - & $3.19 \mathrm{e}-4$ \\
\hline & 5 & 005 & + & $2.31 \pm 0.27$ & 19.71 & -0.33 & - & 0.01 \\
\hline & 5 & 0.05 & - & $5.24 \pm 0.58$ & 47.16 & -5.16 & - & $1.54 \mathrm{e}-6$ \\
\hline & & 05 & + & $10.63 \pm 43.29$ & 11.16 & 0.42 & + & 0.13 \\
\hline & & 0.5 & - & $5.42 \pm 2.06$ & 19.50 & -0.49 & + & 0.07 \\
\hline & & 0005 & + & $2.31 \pm 0.09$ & 25.62 & -1.01 & - & $3.69 \mathrm{e}-4$ \\
\hline & & 0.005 & - & $4.85 \pm 1.03$ & 38.33 & -3.56 & - & $1.54 \mathrm{e}-6$ \\
\hline & 10 & 005 & + & $2.36 \pm 0.21$ & 23.11 & -0.70 & - & $1.11 \mathrm{e}-3$ \\
\hline & 10 & 0.05 & - & $5.00 \pm 0.75$ & 32.58 & -2.67 & - & $1.54 \mathrm{e}-6$ \\
\hline & & 5 & + & $2.62 \pm 1.23$ & 17.95 & -0.17 & - & 0.01 \\
\hline & & 0.5 & - & $6.00 \pm 4.83$ & 20.86 & -0.01 & + & 0.56 \\
\hline 5 & & 0005 & + & $2.29 \pm 0.09$ & 25.71 & -1.01 & - & $3.69 \mathrm{e}-4$ \\
\hline & & 0.005 & - & $5.29 \pm 0.58$ & 49.25 & -5.59 & - & $1.54 \mathrm{e}-6$ \\
\hline & & & + & $2.32 \pm 0.26$ & 21.22 & -0.49 & - & $2.73 e-3$ \\
\hline & 5 & 0.05 & - & $5.05 \pm 0.83$ & 40.08 & -3.85 & - & $1.54 \mathrm{e}-6$ \\
\hline & & 05 & + & $2.39 \pm 0.36$ & 23.28 & -0.71 & - & $1.11 \mathrm{e}-3$ \\
\hline & & 0.5 & - & $6.25 \pm 3.98$ & 18.75 & -0.18 & + & 0.24 \\
\hline
\end{tabular}

Tablo 2'de de görüldüğü gibi test seti için YSA kullanılarak en iyi sonuçlar birinci gizli katmanda $\left(\mathrm{G}_{1}\right) 50$, ikinci gizli katmanda $\left(\mathrm{G}_{2}\right) 10$ nöron içeren ve öğrenme oranı (Öo) 0.5 olan YSA modelinde bulunmuştur. Tablolarda "Norm." ilgili özniteliğin normalize edilip edilmediğini göstermekte olup “+” [0-1] aralığında min-max normalizasyonunun gerçekleştirildiğini göstermektedir. Bunu yanında Wilcoxon rank sum test sonucu $h$ ile belirtilmiş olup değeri ise $p$ ile ifade edilmiştir, null testin $\% 5$ güven aralığında kabul edilmesi "+" işareti ile reddi ise "_" ile gösterilmiştir.

ANFIS'e ait elde edilen zaman serisi şeklinde test seti sonuçları Tablo 3 'te görülmektedir. 
Tablo 3. Zaman serisi biçiminde test seti için ANFIS yöntemine ait farklı parametreler ile elde edilen sonuçlar

\begin{tabular}{|c|c|c|c|c|c|c|}
\hline \multicolumn{2}{|c|}{ Parametreler } & \multirow{2}{*}{ RMSE } & \multirow{2}{*}{ MAPE } & \multirow{2}{*}{$\mathrm{R}^{2}$} & \multicolumn{2}{|c|}{ Wilcoxon Rank } \\
\cline { 1 - 4 } Kural Say1S1 & Norm. & & & $h$ & $p$ \\
\hline \multirow{2}{*}{2} & + & $3.80 \pm 1.3 \mathrm{e}-15$ & 26.21 & -1.06 & - & $3.19 \mathrm{e}-4$ \\
\cline { 2 - 7 } & - & $2.17 \pm 9.0 \mathrm{e}-16$ & 50.16 & -5.31 & - & $1.54 \mathrm{e}-6$ \\
\hline \multirow{2}{*}{3} & + & $\mathbf{0 . 6 5} \pm \mathbf{2 . 3 e}-16$ & $\mathbf{6 . 2 4}$ & $\mathbf{0 . 8 2}$ & + & $\mathbf{0 . 6 4}$ \\
\cline { 2 - 7 } & - & $2.27 \pm 9.0 \mathrm{e}-16$ & 27.90 & -1.26 & - & $1.52 \mathrm{e}-4$ \\
\hline \multirow{2}{*}{4} & + & $0.84 \pm 5.7 \mathrm{e}-16$ & 7.73 & 0.69 & + & 0.39 \\
\cline { 2 - 7 } & - & $2.25 \pm 4.5 \mathrm{e}-16$ & 27.62 & -1.22 & - & $1.77 \mathrm{e}-4$ \\
\hline \multirow{3}{*}{5} & + & $0.95 \pm 1.1 \mathrm{e}-16$ & 8.75 & 0.60 & + & 0.28 \\
\cline { 2 - 7 } & - & $2.27 \pm 1.4 \mathrm{e}-15$ & 27.87 & -1.26 & - & $1.52 \mathrm{e}-4$ \\
\hline \multirow{2}{*}{7} & + & $2.32 \pm 9.0 \mathrm{e}-16$ & 28.56 & -1.36 & - & $9.59 \mathrm{e}-5$ \\
\cline { 2 - 7 } & - & $2.12 \pm 4.5 \mathrm{e}-16$ & 25.91 & -0.96 & - & $4.25 \mathrm{e}-4$ \\
\hline \multirow{2}{*}{11} & + & $1.43 \pm 4.5 \mathrm{e}-16$ & 15.10 & 0.11 & + & 0.24 \\
\cline { 2 - 7 } & - & $3.80 \pm 1.8 \mathrm{e}-15$ & 50.16 & -5.31 & - & $1.54 \mathrm{e}-6$ \\
\hline \multirow{2}{*}{15} & + & $1.75 \pm 0$ & 20.32 & -0.34 & - & $4.99 \mathrm{e}-3$ \\
\cline { 2 - 7 } & - & $3.23 \pm 0$ & 42.43 & -3.58 & - & $1.54 \mathrm{e}-6$ \\
\hline & + & $1.57 \pm 4.5 \mathrm{e}-16$ & 16.34 & -0.08 & - & 0.02 \\
\hline
\end{tabular}

Tablo 3'te de görüldüğü gibi test seti için ANFIS kullanılarak en iyi sonuçlar 3 bulanık kural içeren ANFIS modelinde bulunmuştur. LSTM'ye ait elde edilen zaman serisi şeklinde test seti sonuçları Tablo 4'te görülmektedir.

Tablo 4. Zaman serisi biçiminde test seti için LSTM yöntemine ait farklı parametreler ile elde edilen sonuçlar

\begin{tabular}{|c|c|c|c|c|c|c|c|}
\hline \multicolumn{3}{|c|}{ Parametreler } & \multirow{2}{*}{ RMSE } & \multirow{2}{*}{ MAPE } & \multirow{2}{*}{$\mathrm{R}^{2}$} & \multicolumn{2}{|c|}{ Wilcoxon Rank } \\
\hline $\mathrm{L}_{1}$ & Öo & Norm. & & & & $h$ & $p$ \\
\hline \multirow{6}{*}{50} & \multirow{2}{*}{0.005} & + & $0.83 \pm 0.15$ & 6.10 & 0.83 & + & 0.40 \\
\hline & & - & $5.58 \pm 1.09$ & 33.44 & -2.79 & - & $1.54 \mathrm{e}-6$ \\
\hline & \multirow{2}{*}{0.05} & + & $0.26 \pm 0.11$ & 1.34 & 0.99 & + & 1 \\
\hline & & - & $5.07 \pm 0.66$ & 36.41 & -3.25 & - & $1.54 \mathrm{e}-6$ \\
\hline & \multirow{2}{*}{0.5} & + & $2.71 \pm 1.82$ & 4.42 & 0.96 & + & 0.64 \\
\hline & & - & $8.97 \pm 10.58$ & 19.29 & -0.01 & + & 1 \\
\hline \multirow{6}{*}{45} & \multirow{2}{*}{0.005} & + & $0.86 \pm 0.16$ & 6.05 & 0.83 & + & 0.40 \\
\hline & & - & $5.09 \pm 0.98$ & 40.64 & $-3,95$ & - & $1.54 \mathrm{e}-6$ \\
\hline & \multirow{2}{*}{0.05} & + & $0.25 \pm 0.09$ & 1.11 & 1.00 & + & 1 \\
\hline & & - & $5.21 \pm 0.68$ & 49.78 & -5.70 & - & $1.54 \mathrm{e}-6$ \\
\hline & \multirow{2}{*}{0.5} & + & $1.96 \pm 1.65$ & 2.97 & 0.96 & + & 0.84 \\
\hline & & - & $6.93 \pm 4.85$ & 18.74 & -0.05 & + & 0.56 \\
\hline \multirow{6}{*}{40} & \multirow{2}{*}{0.005} & + & $0.87 \pm 0.15$ & 6.78 & 0.80 & + & 0.36 \\
\hline & & - & $5.15 \pm 1.29$ & 22.15 & -1.08 & - & $2.73 e-3$ \\
\hline & \multirow{2}{*}{0.05} & + & $0.24 \pm 0.08$ & 1.12 & 0.99 & + & 0.98 \\
\hline & & - & $5.05 \pm 0.50$ & 54.85 & -6.80 & - & $1.54 \mathrm{e}-6$ \\
\hline & \multirow{2}{*}{0.5} & + & $2.07 \pm 1.90$ & 1.45 & 0.99 & + & 0.92 \\
\hline & & - & $6.50 \pm 6.08$ & 19.97 & 0.03 & + & 0.56 \\
\hline \multirow{6}{*}{35} & \multirow{2}{*}{0.005} & + & $0.88 \pm 0.15$ & 6.10 & 0.83 & + & 0.40 \\
\hline & & - & $5.08 \pm 0.87$ & 24.07 & -1.43 & - & $3.19 \mathrm{e}-4$ \\
\hline & \multirow{2}{*}{0.05} & + & $0.27 \pm 0.07$ & 1.32 & 0.99 & + & 0.95 \\
\hline & & - & $5.05 \pm 0.67$ & 45.55 & -4.85 & - & $1.54 \mathrm{e}-6$ \\
\hline & \multirow{2}{*}{0.5} & + & $1.99 \pm 1.77$ & 3.99 & 0.94 & + & 0.87 \\
\hline & & - & $5.92 \pm 2.63$ & 18.82 & -0.08 & + & 0.56 \\
\hline \multirow{6}{*}{30} & \multirow{2}{*}{0.005} & + & $0.95 \pm 0.15$ & 7.21 & 0.78 & + & 0.32 \\
\hline & & - & $5.72 \pm 0.93$ & 50.87 & -5.93 & - & $1.54 \mathrm{e}-6$ \\
\hline & \multirow{2}{*}{0.05} & + & $0.28 \pm 0.09$ & 1.59 & 0.99 & + & 0.95 \\
\hline & & - & $5.14 \pm 0.57$ & 40.26 & -3.88 & - & $1.54 \mathrm{e}-6$ \\
\hline & \multirow{2}{*}{0.5} & + & $1.88 \pm 1.90$ & 4.14 & 0.95 & + & 0.61 \\
\hline & & - & $6.17 \pm 2.76$ & 20.18 & -0.67 & - & 0.02 \\
\hline 25 & 0.005 & + & $0.98 \pm 0.17$ & 6.72 & 0.80 & + & 0.34 \\
\hline
\end{tabular}




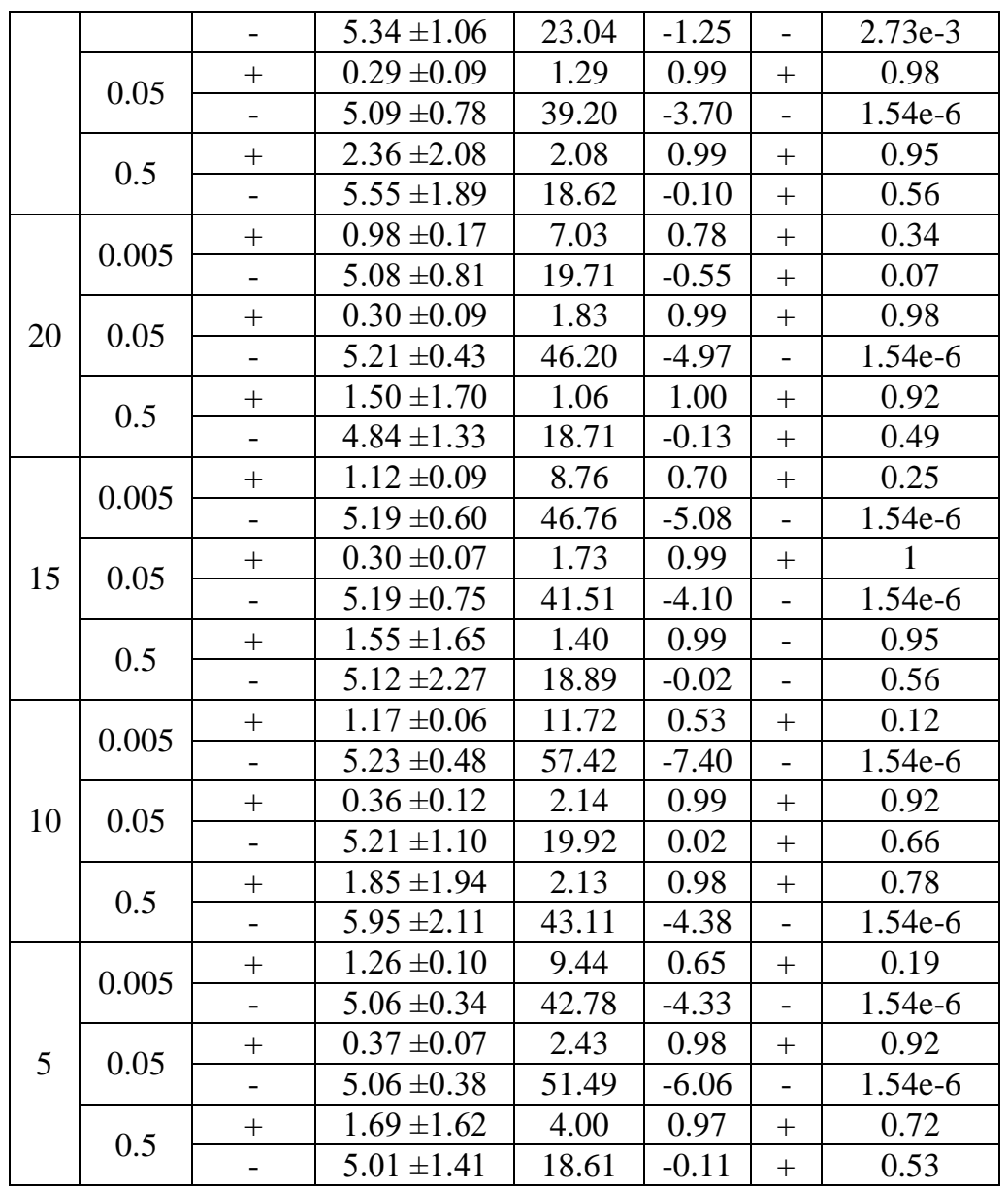

Tablo 4'te de görüldüğü gibi test seti için LSTM kullanılarak en iyi sonuçlar 45 nöronlu, 0.05 öğrenme oranı içeren LSTM modelinde bulunmuştur. LR ve Poisson regresyonuna ait elde edilen zaman serisi şeklinde test seti sonuçları ise sırası ile Tablo 5 ve Tablo 6'da görülmektedir.

Tablo 5. Zaman serisi biçiminde test seti için LR yöntemine ait farklı parametreler ile elde edilen sonuçlar

\begin{tabular}{|c|c|c|c|c|c|}
\hline \multirow{2}{*}{ Norm. } & RMSE & \multirow{2}{*}{ MAPE } & $\mathrm{R}^{2}$ & \multicolumn{2}{|c|}{$\begin{array}{c}\text { Wilcoxon } \\
\text { Rank }\end{array}$} \\
\cline { 5 - 6 }+ & $\begin{array}{c}2.31 \pm 9.0 \mathrm{e}- \\
16\end{array}$ & 28.34 & $\begin{array}{c}- \\
1.33\end{array}$ & - & $9.59 \mathrm{e}-5$ \\
\hline- & $\begin{array}{c}2.31 \pm 9.0 \mathrm{e}- \\
16\end{array}$ & 28.34 & $\begin{array}{c}- \\
1.33\end{array}$ & - & $9.59 \mathrm{e}-5$ \\
\hline
\end{tabular}

Tablo 6. Zaman serisi biçiminde test seti için Poisson yöntemine ait farklı parametreler ile elde edilen sonuçlar

\begin{tabular}{|c|c|c|c|c|c|}
\hline \multirow{2}{*}{ Norm. } & RMSE & \multirow{2}{*}{ MAPE } & \multirow{2}{*}{$\mathrm{R}^{2}$} & \multicolumn{2}{|c|}{$\begin{array}{c}\text { Wilcoxon } \\
\text { Rank }\end{array}$} \\
\cline { 4 - 6 } & & & $h$ & $p$ \\
\hline+ & $1.59 \pm 0.0$ & 17.63 & $\begin{array}{c}- \\
0.11\end{array}$ & + & 0.13 \\
\hline- & $\begin{array}{c}1.59 \pm 4.5 \mathrm{e}- \\
16\end{array}$ & 17.63 & $\begin{array}{c}- \\
0.11\end{array}$ & + & 0.13 \\
\hline
\end{tabular}

Tablo 5-6 incelendiğinde LR ve Poisson regresyonun ANFIS ve LSTM kadar iyi sonuç elde edemediği görülmektedir. Yöntemlere ait sonuçlar incelendiğinde algoritmalarda normalize edilmiş verilerin daha iyi sonuç verdiği görülmüş olup en iyi parametrelere sahip yöntemlerin test seti tahminleri Şekil 5'te görülmektedir.

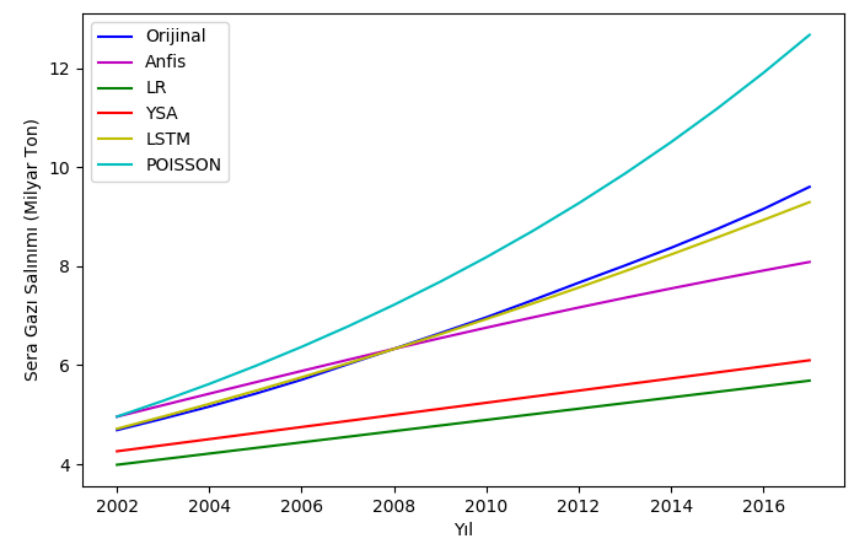

Şekil 5. Algoritmaların test seti tahminleri

Şekil 5 'te de görüldüğü gibi LSTM test seti olan 2002-2017 yılları arasındaki sera gazı emisyon değerlerini daha başarılı tahmin edebilmiştir. Test seti için orijinal veri ile tahminlerin karşılaştırıldığı kutu grafiği Şekil 6'dadır. 


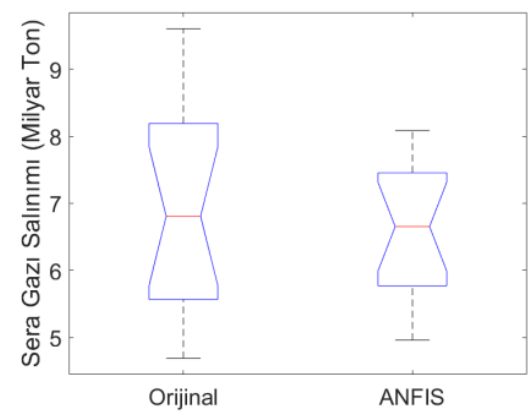

(a)

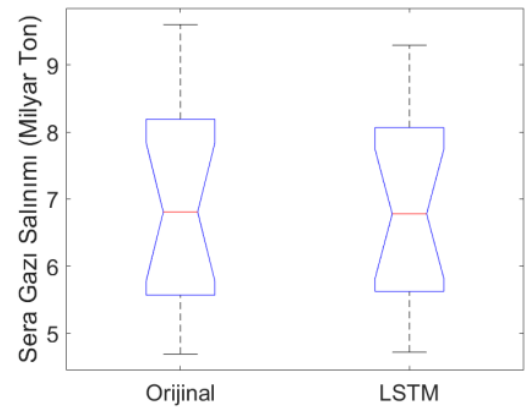

(d)

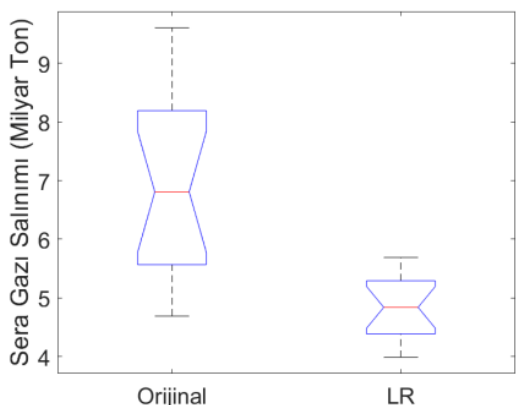

(b)

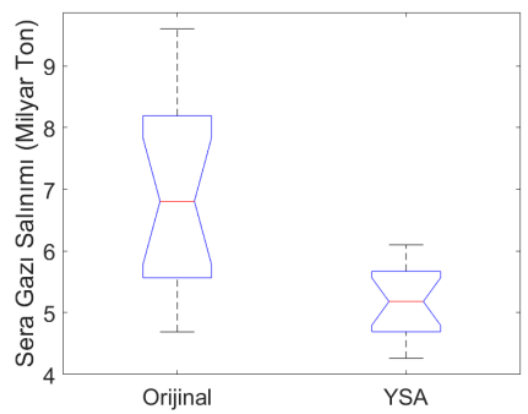

(c)

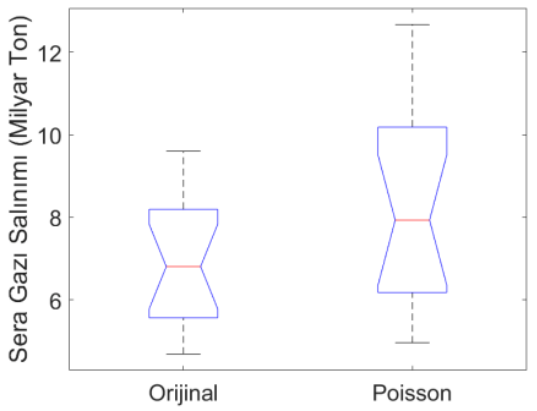

(e)

Şekil 6. Algoritmaların test seti için karşılaştırılmalarına ait kutu grafiği a) ANFIS tahmini, b) LR tahmini, c) YSA tahmini, d) LSTM tahmini, e) Poisson regresyonu tahmini

Şekil 6'da da görüldüğü gibi LSTM orijinal veri ile neredeyse aynı sonuçları içermektedir.
YSA, ANFIS, LSTM, LR ve Poisson regresyonuna ait elde edilen zaman serisi şeklinde eğitim seti sonuçları ise sırasıyla Tablo 7-11'de görülmektedir.

Tablo 7. Zaman serisi biçiminde eğitim seti için YSA yöntemine ait farklı parametreler ile elde edilen sonuçlar

\begin{tabular}{|c|c|c|c|c|c|c|c|c|}
\hline \multicolumn{4}{|c|}{ Parametreler } & \multirow{2}{*}{ RMSE } & \multirow{2}{*}{ MAPE } & \multirow{2}{*}{$\mathrm{R}^{2}$} & \multicolumn{2}{|c|}{ Wilcoxon Rank } \\
\hline $\mathrm{G}_{1}$ & $\mathrm{G}_{2}$ & Öo & Norm. & & & & $h$ & $p$ \\
\hline \multirow{12}{*}{50} & \multirow{6}{*}{10} & \multirow{2}{*}{0.005} & + & $0.28 \pm 0.02$ & 19.69 & 0.93 & + & 0.57 \\
\hline & & & - & $3.25 \pm 2.92$ & 407.23 & -15.71 & - & $6.55 \mathrm{e}-13$ \\
\hline & & \multirow{2}{*}{0.05} & + & $0.30 \pm 0.04$ & 32.65 & 0.90 & + & 0.69 \\
\hline & & & - & $1.27 \pm 0.26$ & 163.28 & -1.44 & - & $2.34 \mathrm{e}-6$ \\
\hline & & \multirow{2}{*}{0.5} & + & $0.30 \pm 0.04$ & 23.43 & 0.92 & + & 0.65 \\
\hline & & & - & $3.84 \pm 9.08$ & 451.32 & -19.84 & - & $6.54 \mathrm{e}-13$ \\
\hline & \multirow{6}{*}{5} & \multirow{2}{*}{0.005} & + & $0.28 \pm 0.01$ & 19.51 & 0.93 & + & 0.57 \\
\hline & & & - & $3.46 \pm 2.69$ & 460.74 & -20.78 & - & $6.55 \mathrm{e}-13$ \\
\hline & & \multirow{2}{*}{0.05} & + & $0.30 \pm 0.02$ & 25.52 & 0.92 & + & 0.91 \\
\hline & & & - & $1.28 \pm 0.14$ & 151.60 & -1.11 & - & $1.18 \mathrm{e}-5$ \\
\hline & & \multirow{2}{*}{0.5} & + & $0.32 \pm 0.06$ & 23.33 & 0.92 & + & 0.66 \\
\hline & & & - & $4.67 \pm 9.28$ & 285.83 & -6.83 & - & $6.55 \mathrm{e}-13$ \\
\hline \multirow{12}{*}{40} & \multirow{6}{*}{10} & \multirow{2}{*}{0.005} & + & $0.28 \pm 0.02$ & 20.60 & 0.92 & + & 0.45 \\
\hline & & & - & $3.11 \pm 2.30$ & 379.87 & -13.40 & - & $6.55 \mathrm{e}-13$ \\
\hline & & \multirow{2}{*}{0.05} & + & $0.31 \pm 0.04$ & 29.52 & 0.90 & + & 0.86 \\
\hline & & & - & $1.36 \pm 0.37$ & 266.94 & -5.78 & - & $6.55 \mathrm{e}-13$ \\
\hline & & \multirow{2}{*}{0.5} & + & $0.31 \pm 0.04$ & 24.65 & 0.88 & + & 0.38 \\
\hline & & & - & $2.35 \pm 1.95$ & 483.02 & -22.94 & - & $6.54 \mathrm{e}-13$ \\
\hline & \multirow{6}{*}{5} & \multirow{2}{*}{0.005} & + & $0.28 \pm 0.02$ & 19.65 & 0.93 & + & 0.57 \\
\hline & & & - & $1.98 \pm 0.99$ & 269.03 & -5.89 & - & $6.55 \mathrm{e}-13$ \\
\hline & & \multirow{2}{*}{0.05} & + & $0.30 \pm 0.03$ & 26.97 & 0.88 & + & 0.47 \\
\hline & & & - & $1.26 \pm 0.11$ & 139.32 & -0.80 & - & $9.17 e-5$ \\
\hline & & \multirow{2}{*}{0.5} & + & $0.32 \pm 0.04$ & 25.07 & 0.90 & + & 0.56 \\
\hline & & & - & $2.25 \pm 2.48$ & 295.48 & -7.38 & - & $6.55 \mathrm{e}-13$ \\
\hline
\end{tabular}




\begin{tabular}{|c|c|c|c|c|c|c|c|c|}
\hline \multirow{12}{*}{30} & \multirow{6}{*}{10} & \multirow{2}{*}{0.005} & + & $0.28 \pm 0.02$ & 22.36 & 0.90 & + & 0.45 \\
\hline & & & - & $3.42 \pm 3.13$ & 419.11 & -16.78 & - & $6.55 \mathrm{e}-13$ \\
\hline & & \multirow{2}{*}{0.05} & + & $0.30 \pm 0.03$ & 24.25 & 0.90 & + & 0.50 \\
\hline & & & - & $1.26 \pm 0.12$ & 145.79 & -0.96 & - & $1.63 \mathrm{e}-5$ \\
\hline & & \multirow{2}{*}{0.5} & + & $0.31 \pm 0.06$ & 22.63 & 0.93 & + & $2.49 \mathrm{e}-7$ \\
\hline & & & - & $7.50 \pm 22.19$ & 168.56 & -1.60 & - & 0.78 \\
\hline & \multirow{6}{*}{5} & \multirow{2}{*}{0.005} & + & $0.28 \pm 0.01$ & 19.59 & 0.94 & + & 0.73 \\
\hline & & & - & $3.11 \pm 2.61$ & 402.06 & -15.26 & - & $6.55 \mathrm{e}-13$ \\
\hline & & \multirow{2}{*}{0.05} & + & $0.30 \pm 0.04$ & 22.25 & 0.89 & + & 0.37 \\
\hline & & & - & $1.24 \pm 0.12$ & 150.12 & -1.07 & - & $1.63 e-5$ \\
\hline & & \multirow{2}{*}{0.5} & + & $0.32 \pm 0.05$ & 27.13 & 0.88 & + & 0.52 \\
\hline & & & - & $7.47 \pm 25.86$ & 168.78 & -1.61 & - & $2.85 \mathrm{e}-7$ \\
\hline \multirow{12}{*}{20} & \multirow{6}{*}{10} & \multirow{2}{*}{0.005} & + & $0.28 \pm 0.02$ & 20.29 & 0.93 & + & 0.62 \\
\hline & & & - & $1.62 \pm 0.53$ & 271.39 & -6.02 & - & $6.55 e-13$ \\
\hline & & \multirow{2}{*}{0.05} & + & $0.31 \pm 0.04$ & 25.72 & 0.88 & + & 0.45 \\
\hline & & & - & $1.26 \pm 0.16$ & 173.30 & -1.75 & - & $2.85 \mathrm{e}-7$ \\
\hline & & \multirow{2}{*}{0.5} & + & $0.31 \pm 0.05$ & 23.63 & 0.89 & + & 0.42 \\
\hline & & & - & $5.28 \pm 12.99$ & 413.57 & -16.21 & - & $6.54 \mathrm{e}-13$ \\
\hline & \multirow{6}{*}{5} & \multirow{2}{*}{0.005} & + & $0.28 \pm 0.01$ & 19.62 & 0.94 & + & 0.79 \\
\hline & & & - & $2.39 \pm 1.85$ & 404.16 & -15.45 & - & $6.55 \mathrm{e}-13$ \\
\hline & & \multirow{2}{*}{0.05} & + & $0.29 \pm 0.03$ & 20.94 & 0.93 & + & 0.62 \\
\hline & & & - & $1.35 \pm 0.25$ & 204.90 & -2.90 & - & $2.60 \mathrm{e}-9$ \\
\hline & & \multirow{2}{*}{0.5} & + & $0.34 \pm 0.06$ & 23.18 & 0.89 & + & 0.42 \\
\hline & & & - & $1.45 \pm 0.44$ & 184.54 & -2.14 & - & $2.95 \mathrm{e}-8$ \\
\hline \multirow{12}{*}{10} & \multirow{6}{*}{10} & \multirow{2}{*}{0.005} & + & $0.28 \pm 0.01$ & 20.06 & 0.94 & + & 0.69 \\
\hline & & & - & $2.05 \pm 1.61$ & 378.00 & -13.24 & - & $6.55 e-13$ \\
\hline & & 005 & + & $0.30 \pm 0.03$ & 25.13 & 0.92 & + & 0.81 \\
\hline & & 0.03 & - & $1.35 \pm 0.19$ & 175.10 & -1.81 & - & $2.85 \mathrm{e}-7$ \\
\hline & & 05 & + & $0.34 \pm 0.06$ & 30.45 & 0.83 & + & 0.41 \\
\hline & & 0.5 & - & $2.46 \pm 3.07$ & 292.31 & -7.23 & - & $6.55 e-13$ \\
\hline & & 0005 & + & $0.28 \pm 0.01$ & 20.26 & 0.93 & + & 0.65 \\
\hline & & 0.005 & - & $1.82 \pm 1.23$ & 277.83 & -6.38 & - & $6.55 \mathrm{e}-13$ \\
\hline & & 005 & + & $0.30 \pm 0.03$ & 26.63 & 0.91 & + & 0.81 \\
\hline & 5 & 0.05 & - & $1.30 \pm 0.17$ & 168.08 & -1.59 & - & $3.03 \mathrm{e}-7$ \\
\hline & & 05 & + & $3.46 \pm 15.81$ & 43.61 & 0.79 & + & 0.90 \\
\hline & & 0.5 & - & $2.20 \pm 1.76$ & 338.62 & -10.27 & - & $6.55 \mathrm{e}-13$ \\
\hline & & 0005 & + & $0.28 \pm 0.01$ & 18.73 & 0.94 & + & 0.61 \\
\hline & & 0.005 & - & $1.86 \pm 1.86$ & 208.80 & -3.06 & - & $1.57 \mathrm{e}-9$ \\
\hline & 10 & 005 & + & $0.29 \pm 0.02$ & 21.15 & 0.93 & + & 0.72 \\
\hline & 10 & 0.05 & - & $1.38 \pm 0.29$ & 236.68 & -4.27 & - & $1.22 \mathrm{e}-11$ \\
\hline & & 05 & + & $0.41 \pm 0.38$ & 27.23 & 0.90 & + & 0.70 \\
\hline 5 & & 0.5 & - & $3.40 \pm 4.59$ & 444.36 & -19.14 & - & $6.55 \mathrm{e}-13$ \\
\hline 5 & & & + & $0.28 \pm 0.01$ & 18.66 & 0.94 & + & $2.34 \mathrm{e}-6$ \\
\hline & & 0.005 & - & $1.30 \pm 0.19$ & 158.58 & $-1,30$ & - & 0.69 \\
\hline & 5 & & + & $0.30 \pm 0.03$ & 23.17 & 0.92 & + & 0.71 \\
\hline & 5 & 0.05 & - & $1.40 \pm 0.40$ & 200.58 & -2.73 & - & $2.60 \mathrm{e}-9$ \\
\hline & & & + & $0.31 \pm 0.06$ & 21.41 & 0.94 & + & 0.75 \\
\hline & & 0.5 & - & $3.19 \pm 5.24$ & 374.18 & -12.93 & - & $6.55 \mathrm{e}-13$ \\
\hline
\end{tabular}


Tablo 8. Zaman serisi biçiminde eğitim seti için ANFIS yöntemine ait farklı parametreler ile elde edilen sonuçlar

\begin{tabular}{|c|c|c|c|c|c|c|}
\hline \multicolumn{2}{|c|}{ Parametreler } & \multirow{2}{*}{ RMSE } & \multirow{2}{*}{ MAPE } & \multirow{2}{*}{$\mathrm{R}^{2}$} & \multicolumn{2}{|c|}{ Wilcoxon Rank } \\
\cline { 1 - 4 } Kural Say1s1 & Norm. & & & $h$ & $p$ \\
\hline \multirow{2}{*}{2} & + & $0.27 \pm 0$ & 17.50 & 0.95 & + & 0.41 \\
\cline { 2 - 7 } & - & $0.65 \pm 0$ & 39.24 & 0.69 & + & 0.93 \\
\hline \multirow{2}{*}{3} & + & $0.11 \pm 2.8 \mathrm{e}-17$ & 4.43 & 0.99 & + & 0.82 \\
\cline { 2 - 7 } & - & $0.26 \pm 1.1 \mathrm{e}-16$ & 17.24 & 0.95 & + & 0.93 \\
\hline \multirow{2}{*}{4} & + & $0.10 \pm 5.6 \mathrm{e}-17$ & 3.78 & 0.99 & + & 0.90 \\
\cline { 2 - 7 } & - & $0.26 \pm 0$ & 17.02 & 0.95 & + & 0.93 \\
\hline \multirow{3}{*}{5} & + & $0.10 \pm 0$ & 3.20 & 0.99 & + & 0.93 \\
\cline { 2 - 7 } & - & $0.26 \pm 0$ & 17.22 & 0.95 & + & 0.93 \\
\hline \multirow{2}{*}{7} & + & $0.27 \pm 0$ & 17.34 & 0.95 & + & 0.93 \\
\cline { 2 - 7 } & - & $0.24 \pm 1.1 \mathrm{e}-16$ & 15.64 & 0.96 & + & 0.94 \\
\hline \multirow{2}{*}{11} & + & $1.23 \pm 6.8 \mathrm{e}-16$ & 64.05 & -0.10 & - & $2.09 \mathrm{e}-3$ \\
\cline { 2 - 7 } & - & $0.65 \pm 3.4 \mathrm{e}-16$ & 39.24 & 0.69 & + & 0.41 \\
\cline { 2 - 7 } & + & $0.12 \pm 4.2 \mathrm{e}-17$ & 3.61 & 0.99 & + & 0.93 \\
\hline \multirow{2}{*}{19} & - & $0.54 \pm 2.3 \mathrm{e}-16$ & 30.16 & 0.78 & + & 0.19 \\
\cline { 2 - 7 } & + & $0.10 \pm 0$ & 4.70 & 0.99 & + & 0.81 \\
\hline
\end{tabular}

Tablo 9. Zaman serisi biçiminde eğitim seti için LSTM yöntemine ait farklı parametreler ile elde edilen sonuçlar

\begin{tabular}{|c|c|c|c|c|c|c|c|}
\hline \multicolumn{3}{|c|}{ Parametreler } & \multirow{2}{*}{ RMSE } & \multirow{2}{*}{ MAPE } & \multirow{2}{*}{$\mathrm{R}^{2}$} & \multicolumn{2}{|c|}{ Wilcoxon Rank } \\
\hline $\mathrm{L}_{1}$ & Öo & Norm. & & & & $h$ & $p$ \\
\hline \multirow{6}{*}{50} & \multirow{2}{*}{0.005} & + & $0.05 \pm 0.03$ & 1.11 & 1.00 & + & 0.96 \\
\hline & & - & $1.57 \pm 0.55$ & 232.43 & -4.08 & - & $1.22 \mathrm{e}-11$ \\
\hline & \multirow{2}{*}{0.05} & + & $0.03 \pm 0.03$ & 1.11 & 1.00 & + & 0.91 \\
\hline & & - & $1.32 \pm 0.29$ & 218.03 & -3.44 & - & $1.94 \mathrm{e}-10$ \\
\hline & \multirow{2}{*}{0.5} & + & $0.54 \pm 0.57$ & 7.11 & 0.99 & + & 0.71 \\
\hline & & - & $6.41 \pm 9.99$ & 413.23 & -16.20 & - & $6.55 e-13$ \\
\hline \multirow{6}{*}{45} & \multirow{2}{*}{0.005} & + & $0.06 \pm 0.03$ & 1.25 & 1.00 & + & 0.96 \\
\hline & & - & $1.50 \pm 0.32$ & 197.79 & -2.62 & - & $2.79 \mathrm{e}-9$ \\
\hline & \multirow{2}{*}{0.05} & + & $0.03 \pm 0.02$ & 0.69 & 1.00 & + & 0.96 \\
\hline & & - & $1.34 \pm 0.21$ & 156.11 & -1.23 & - & $2.34 \mathrm{e}-6$ \\
\hline & \multirow{2}{*}{0.5} & + & $0.31 \pm 0.44$ & 3.82 & 1.00 & + & 0.79 \\
\hline & & - & $4.10 \pm 5.22$ & 389.07 & -14.19 & - & $6.55 \mathrm{e}-13$ \\
\hline \multirow{6}{*}{40} & \multirow{2}{*}{0.005} & + & $0.06 \pm 0.03$ & 1.12 & 1.00 & + & 0.97 \\
\hline & & - & $1.68 \pm 0.57$ & 304.10 & -7.94 & - & $6.55 \mathrm{e}-13$ \\
\hline & \multirow{2}{*}{0.05} & + & $0.03 \pm 0.02$ & 0.91 & 1.00 & + & 0.94 \\
\hline & & - & $1.27 \pm 0.13$ & 134.37 & -0.68 & - & $9.63 e-5$ \\
\hline & \multirow{2}{*}{0.5} & + & $0.36 \pm 0.45$ & 2.77 & 1.00 & + & 0.82 \\
\hline & & - & $4.46 \pm 7.50$ & 427.14 & -17.55 & - & $6.55 \mathrm{e}-13$ \\
\hline \multirow{6}{*}{35} & \multirow{2}{*}{0.005} & + & $0.06 \pm 0.03$ & 1.27 & 1.00 & + & 0.94 \\
\hline & & - & $1.41 \pm 0.45$ & 286.51 & -6.88 & - & $6.55 e-13$ \\
\hline & \multirow{2}{*}{0.05} & + & $0.03 \pm 0.03$ & 1.10 & 1.00 & + & 0.93 \\
\hline & & - & $1.34 \pm 0.24$ & 175.06 & -1.81 & - & $2.85 \mathrm{e}-7$ \\
\hline & \multirow{2}{*}{0.5} & + & $0.36 \pm 0.47$ & 4.21 & 0.99 & + & 0.88 \\
\hline & & - & $3.22 \pm 3.22$ & 390.38 & -14.24 & - & $6.55 \mathrm{e}-13$ \\
\hline \multirow{6}{*}{30} & \multirow{2}{*}{0.005} & + & $0.07 \pm 0.03$ & 1.39 & 1.00 & + & 0.95 \\
\hline & & - & $1.51 \pm 0.53$ & 151.49 & -1.11 & - & $1.25 e-5$ \\
\hline & \multirow{2}{*}{0.05} & + & $0.03 \pm 0.02$ & 1.54 & 1.00 & + & 0.89 \\
\hline & & - & $1.28 \pm 0.23$ & 199.55 & -2.69 & - & $2.60 \mathrm{e}-9$ \\
\hline & \multirow{2}{*}{0.5} & + & $0.37 \pm 0.48$ & 33.17 & 0.90 & + & 0.19 \\
\hline & & - & $3.43 \pm 3.85$ & 329.26 & -9.59 & - & $6.55 e-13$ \\
\hline \multirow{3}{*}{25} & \multirow{2}{*}{0.005} & + & $0.07 \pm 0.03$ & 1.37 & 1.00 & + & 0.94 \\
\hline & & - & $1.52 \pm 0.52$ & 295.18 & -7.39 & - & $6.55 e-13$ \\
\hline & 0.05 & + & $0.03 \pm 0.05$ & 0.91 & 1.00 & + & 0.96 \\
\hline
\end{tabular}




\begin{tabular}{|c|c|c|c|c|c|c|c|}
\hline & & - & $1.38 \pm 0.32$ & 204.50 & -2.88 & - & $2.60 \mathrm{e}-9$ \\
\hline & \multirow{2}{*}{0.5} & + & $0.47 \pm 0.56$ & 2.33 & 1.00 & + & 0.86 \\
\hline & & - & $1.83 \pm 1.40$ & 379.97 & -13.44 & - & $6.55 \mathrm{e}-13$ \\
\hline \multirow{6}{*}{20} & \multirow{2}{*}{0.005} & + & $0.07 \pm 0.03$ & 1.26 & 1.00 & + & 0.98 \\
\hline & & - & $1.36 \pm 0.52$ & 337.89 & -10.20 & - & $6.55 \mathrm{e}-13$ \\
\hline & \multirow{2}{*}{0.05} & + & $0.03 \pm 0.02$ & 1.84 & 1.00 & + & 0.88 \\
\hline & & - & $1.23 \pm 0.15$ & 171.98 & -1.71 & - & $2.85 \mathrm{e}-7$ \\
\hline & \multirow{2}{*}{0.5} & + & $0.23 \pm 0.39$ & 2.04 & 1.00 & + & 0.93 \\
\hline & & - & $1.70 \pm 0.87$ & 382.02 & -13.55 & - & $6.55 e-13$ \\
\hline \multirow{6}{*}{15} & \multirow{2}{*}{0.005} & + & $0.10 \pm 0.02$ & 1.71 & 1.00 & + & 0.99 \\
\hline & & - & $1.30 \pm 0.21$ & 169.50 & -1.63 & - & $2.85 \mathrm{e}-7$ \\
\hline & \multirow{2}{*}{0.05} & + & $0.03 \pm 0.01$ & 2.38 & 1.00 & + & 0.84 \\
\hline & & - & $1.36 \pm 0.30$ & 193.73 & -2.47 & - & $2.11 \mathrm{e}-8$ \\
\hline & \multirow{2}{*}{0.5} & + & $0.26 \pm 0.39$ & 4.56 & 1.00 & + & 0.77 \\
\hline & & - & $2.83 \pm 3.29$ & 398.76 & -14.99 & - & $6.55 \mathrm{e}-13$ \\
\hline \multirow{6}{*}{10} & \multirow{2}{*}{0.005} & + & $0.10 \pm 0.01$ & 5.11 & 1.00 & + & 0.93 \\
\hline & & - & $1.26 \pm 0.16$ & 123.88 & -0.47 & - & 0.00 \\
\hline & \multirow{2}{*}{0.05} & + & $0.03 \pm 0.03$ & 2.53 & 1.00 & + & 0.85 \\
\hline & & - & $1.53 \pm 0.78$ & 428.11 & -17.61 & - & $6.55 \mathrm{e}-13$ \\
\hline & \multirow{2}{*}{0.5} & + & $0.30 \pm 0.47$ & 3.75 & 1.00 & + & 0.91 \\
\hline & & - & $1.95 \pm 1.63$ & 184.72 & -2.14 & - & $2.95 \mathrm{e}-8$ \\
\hline \multirow{6}{*}{5} & \multirow{2}{*}{0.005} & + & $0.10 \pm 0.02$ & 1.75 & 1.00 & + & 0.96 \\
\hline & & - & $1.25 \pm 0.16$ & 116.91 & -0.34 & - & $2.09 \mathrm{e}-3$ \\
\hline & \multirow{2}{*}{0.05} & + & $0.02 \pm 0.01$ & 1.14 & 1.00 & + & 0.89 \\
\hline & & - & $1.22 \pm 0.09$ & 136.11 & -0.72 & - & $9.63 e-5$ \\
\hline & \multirow{2}{*}{0.5} & + & $0.31 \pm 0.42$ & 10.12 & 0.96 & + & 0.89 \\
\hline & & - & $2.08 \pm 2.28$ & 378.52 & -13.31 & - & $6.55 \mathrm{e}-13$ \\
\hline
\end{tabular}

Tablo 10. Zaman serisi biçiminde eğitim seti için LR yöntemine ait farklı parametreler ile elde edilen sonuçlar

\begin{tabular}{|c|c|c|c|c|c|}
\hline \multirow{2}{*}{ Norm. } & RMSE & \multirow{2}{*}{ MAPE } & \multirow{2}{*}{$\mathrm{R}^{2}$} & \multicolumn{2}{|c|}{$\begin{array}{c}\text { Wilcoxon } \\
\text { Rank }\end{array}$} \\
\cline { 4 - 6 }+ & $\begin{array}{c}0.27 \pm 1.1 \mathrm{e}- \\
16\end{array}$ & 17.53 & 0.95 & + & 0.93 \\
\hline- & $\begin{array}{c}0.27 \pm 1.1 \mathrm{e}- \\
16\end{array}$ & 17.53 & 0.95 & + & 0.93 \\
\hline
\end{tabular}

Tablo 11. Zaman serisi biçiminde eğitim seti için Poisson yöntemine ait farklı parametreler ile elde edilen sonuçlar

\begin{tabular}{|c|c|c|c|c|c|}
\hline \multirow{2}{*}{ Norm. } & RMSE & \multirow{2}{*}{ MAPE } & \multirow{2}{*}{$\mathrm{R}^{2}$} & \multicolumn{2}{|c|}{$\begin{array}{c}\text { Wilcoxon } \\
\text { Rank }\end{array}$} \\
\cline { 5 - 6 } & & & & $h$ & $p$ \\
\hline+ & $\begin{array}{c}0.05 \pm 2.8 \mathrm{e}- \\
17\end{array}$ & 3.02 & 0.99 & + & 1.0 \\
\hline- & $\begin{array}{c}0.05 \pm 2.1 \mathrm{e}- \\
17\end{array}$ & 3.02 & 0.99 & + & 1.0 \\
\hline
\end{tabular}

Tablo 7-11 incelendiğinde test setinde tespit edilen en uygun parametrelere sahip ve normalize edilmiş algoritmaların eğitim setinde de başarılı sonuçlar verdiği görülmekte olup bu tahminler Şekil 7'de görülmektedir.

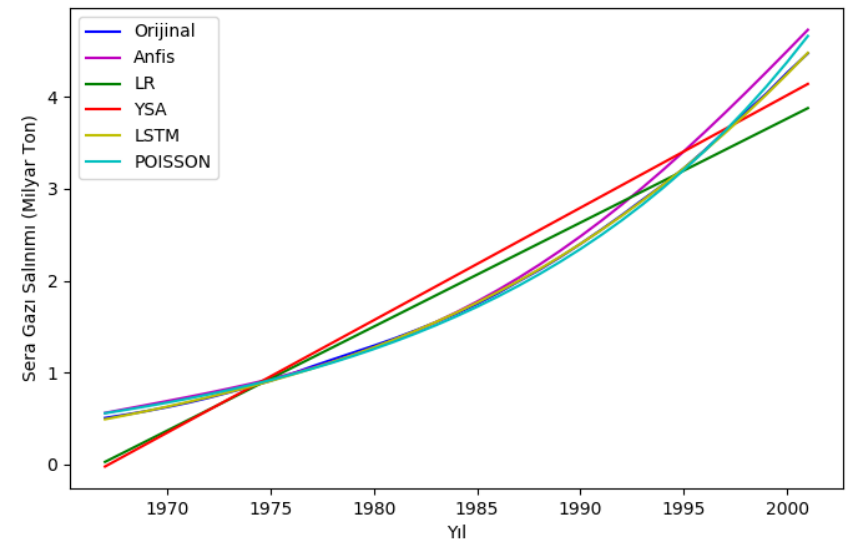

Şekil 7. Algoritmaların eğitim seti tahminleri

Şekil 7'de de görüldüğü gibi genel olarak tüm yöntemler eğitim setinde iyi sonuçlar vermesine rağmen LSTM, Poisson regresyonu ve ANFIS eğitim seti olan 1967-2001 yılları arasındaki sera gazı emisyon değerlerini daha başarılı öğrenebilmişlerdir. Eğitim seti için orijinal veri ile tahmin değerlerinin karşılaştırmasını içeren kutu grafiği ise Şekil 8'de görülmektedir. 


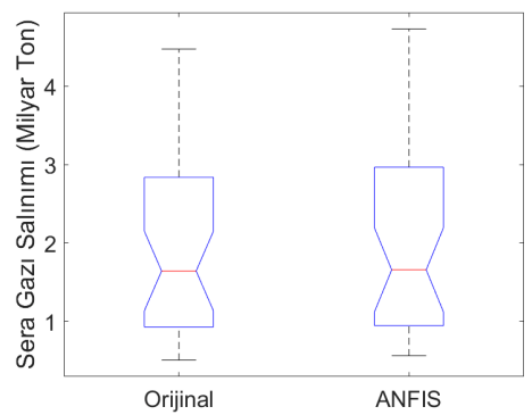

(a)

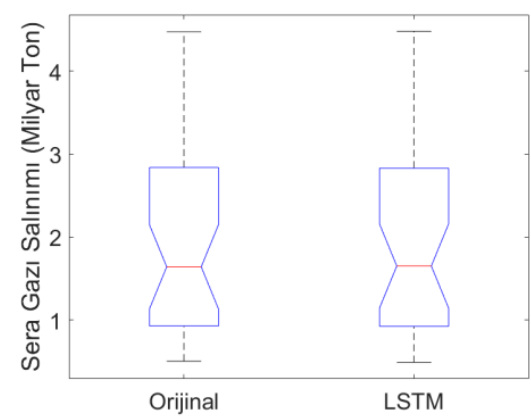

(d)

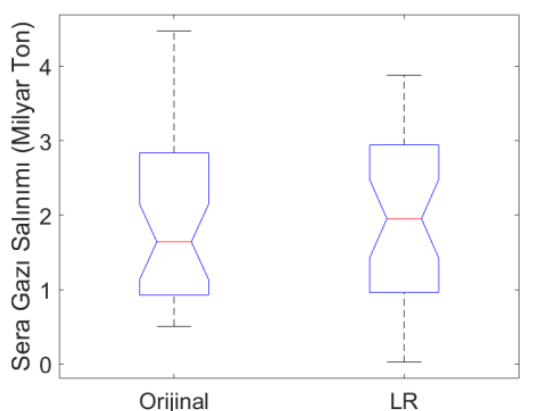

(b)

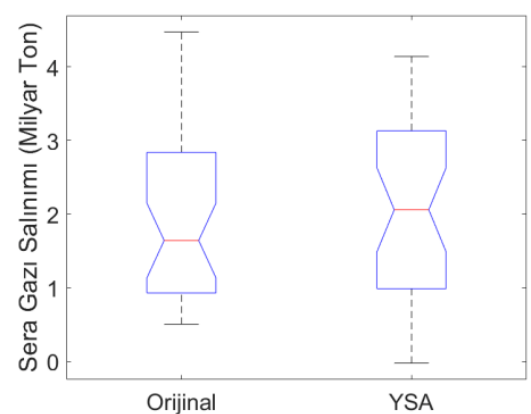

(c)

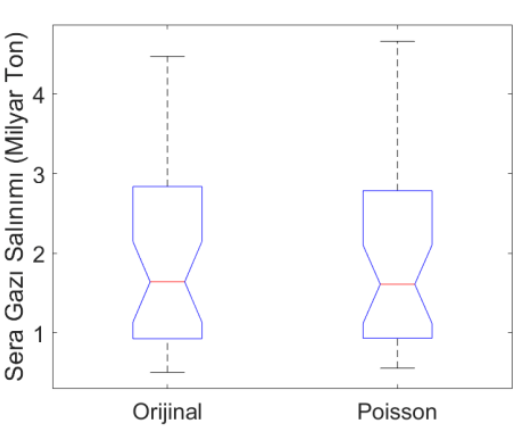

(e)

Şekil 8. Algoritmaların eğitim seti için karş̧laştırılmalarına ait kutu grafiği a) ANFIS tahmini, b) LR tahmini, c) YSA tahmini, d) LSTM tahmini, e) Poisson regresyonu tahmini

Şekil 8'de de görüldüğü gibi LSTM, Poisson regresyonu ve ANFIS eğitim setinde iyi sonuçlar vermişlerdir. Özellikle LSTM'nin elde ettiği sonuçlar neredeyse orijinal veri ile aynıdır.

Zaman serisi şeklinde gerçekleştirilen testlerden sonra veri setinin kendi içerisinde de istatistiksel olarak başarısını ölçmek için 10-kat çapraz doğrulama uygulanmıştır. Makine öğrenimi algoritmalarının belirlenen en uygun parametreleri için 10-kat çapraz doğrulama sonuçları Tablo 12'de görülmektedir.

Tablo 12. En uygun parametrelere sahip yöntemlerin 10-kat çapraz doğrulama sonuçları

\begin{tabular}{|c|c|c|c|c|c|}
\hline \multirow{2}{*}{ Yöntem } & \multirow{2}{*}{ RMSE } & \multirow{2}{*}{ MAPE } & \multirow{2}{*}{$\mathrm{R}^{2}$} & \multicolumn{2}{|c|}{ Wilcoxon Rank } \\
\cline { 5 - 6 } & & & & $h$ & $p$ \\
\hline ANFIS & $0.09 \pm 0.04$ & 2.97 & 0.99 & + & 0.98 \\
\hline LR & $0.71 \pm 0.23$ & 39.44 & 0.92 & + & 0.88 \\
\hline YSA & $0.76 \pm 0.21$ & 40.47 & 0.91 & + & 0.84 \\
\hline LSTM & $0.02 \pm 0.01$ & 0.75 & 1.00 & + & 0.99 \\
\hline Poisson & $0.18 \pm 0.09$ & 6.76 & 0.99 & + & 0.95 \\
\hline
\end{tabular}

Tablo 12'de de görüldüğü gibi yine en iyi sonuçlar LSTM ile elde edilmiştir. Algoritmaların 10-kat çapraz doğrulama tahminleri Şekil 9'da görülmektedir.

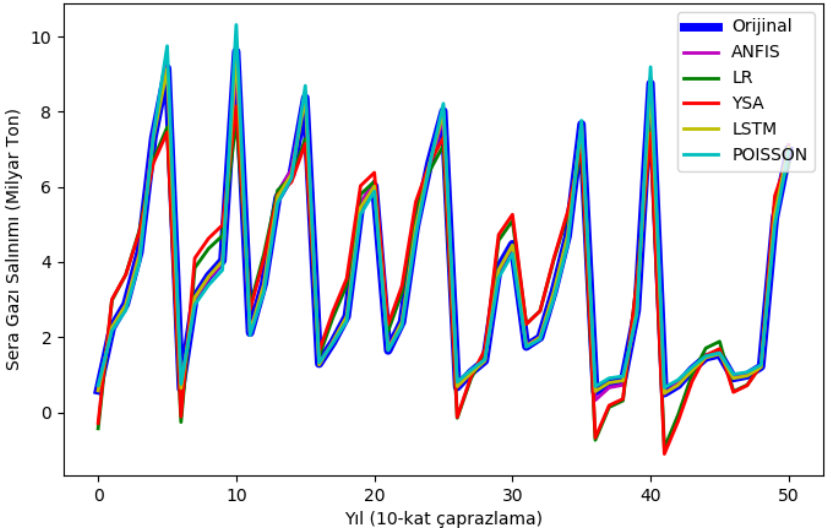

Şekil 9. Algoritmaların 10-kat çapraz doğrulama tahminleri

Şekil 9'da da görüldüğü gibi ANFIS, LSTM ve Poisson regresyonunun çapraz doğrulama tahminleri başarılı görülmekle birlikte Tablo 12'de elde edilen en başarılı sonuç LSTM'ye aittir. Çapraz doğrulama için orijinal veri ile tahmin değerlerinin karşılaştırmasını içeren kutu grafiği ise Şekil 10'da görülmektedir. 


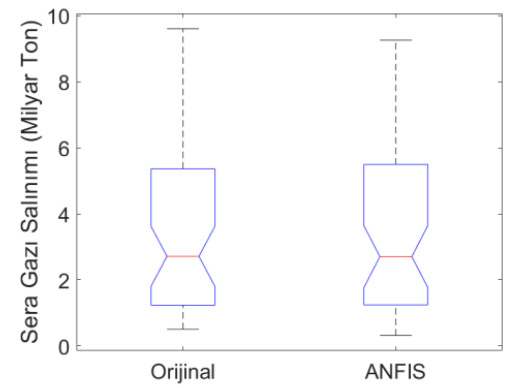

(a)

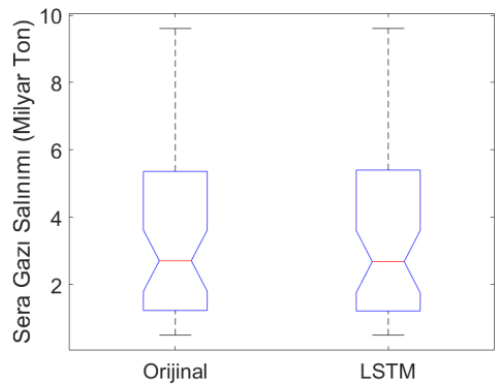

(d)

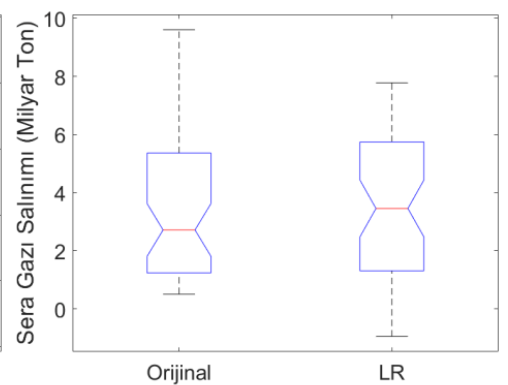

(b)

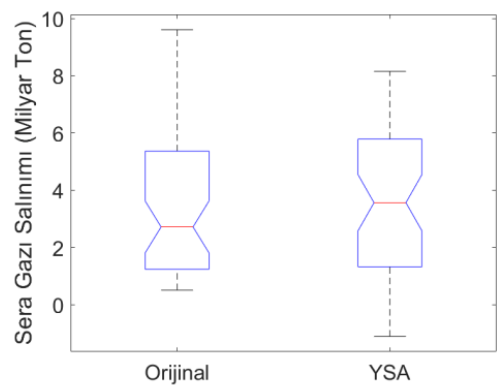

(c)

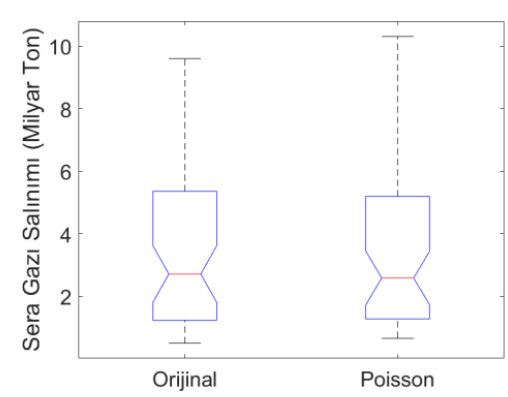

(e)

Şekil 10. Algoritmaların 10-kat çapraz doğrulama için karşılaştırılmalarına ait kutu grafiği a) ANFIS tahmini, b) LR tahmini, c) YSA tahmini, d) LSTM tahmini, e) Poisson regresyonu tahmini

Şekil 10'da da görüldüğü gibi LSTM, Poisson regresyonu ve ANFIS çapraz doğrulamada iyi sonuçlar verirken en başarılı sonuç LSTM'ye ait olarak görülmektedir. Zaman serisi ve 10-kat çapraz doğrulama sonuçları incelendiğinde en başarılı algoritmanın LSTM'ye ait olduğu görülmekte olup bunun yanında ANFIS ve Poisson regresyonu da LR ve YSA'ya göre daha iyi sonuç elde etmişlerdir. En kötü sonuçlar LR yöntemine ait olup, bu sonuçlar sayesinde sera gazı emisyonunun zamana bağlı lineer değişmediği görülmekte olup ilgili değerler lineer olmayan şekilde artış göstermektedir. Elde edilen başarılı sonuçlar 1şığında en uygun parametreler ile geliştirilen modeller Türkiye'nin 2018-2031 yıllarına ait sera gazı emisyonunu tahmin etmek için kullanılmıştır. Sadece ileriki 14 yıla ait tahminin gerçekleştirilme sebebi ilgili tahmininde bir zaman serisi olması ve zaman serisi testlerinin veri seti üzerinde $\% 70$ eğitim ve $\% 30$ test olacak şekilde modellenmesidir. Bu sebeple bu aşamada 1967-2017 yılları oluşturulacak modeller için eğitim olarak kullanılırken, eğitim setinin yaklaşık \%30'una karşılık gelen 2018-2031 yılları ise tahmin edilecek veriyi oluşturmaktadır. 1767-2017 yıllarını kapsayan ve en uygun parametreli algoritmaların eğitim sonuçları Tablo 13'te görülmektedir.

Tablo 13. En uygun parametrelere sahip yöntemlerin 19672017 yılları için eğitim sonuçları

\begin{tabular}{|c|c|c|c|c|c|}
\hline \multirow{2}{*}{ Yöntem } & \multirow{2}{*}{ RMSE } & \multirow{2}{*}{ MAPE } & \multirow{2}{*}{$\mathrm{R}^{2}$} & \multicolumn{2}{|c|}{ Wilcoxon Rank } \\
\cline { 5 - 6 } & & & & $H$ & $P$ \\
\hline ANFIS & 0.07 & 1.60 & 1.00 & + & 0.95 \\
\hline LR & 0.73 & 37.32 & 0.92 & + & 0.88 \\
\hline YSA & 0.75 & 33.04 & 0.92 & + & 0.62 \\
\hline LSTM & 0.03 & 0.77 & 1.00 & + & 0.94 \\
\hline Poisson & 0.19 & 6.41 & 0.99 & + & 0.95 \\
\hline
\end{tabular}

Tablo 13'te de görüldüğü gibi LSTM, Poisson regresyonu ve ANFIS iyi sonuç vermelerine rağmen yine LSTM elde ettiği başarılı sonuçlar ile öne çıkmıştır. İlgili eğitime ait tahminler Şekil 11'de görülmektedir.

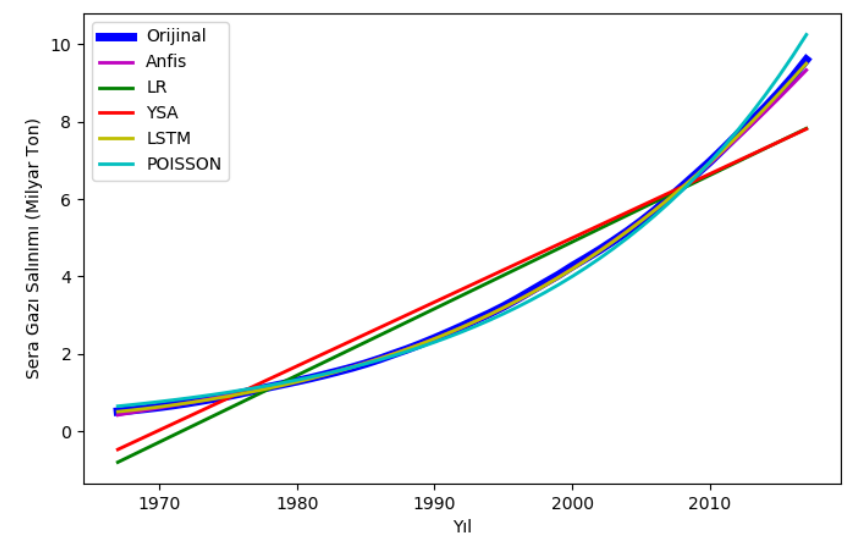

Şekil 11. Algoritmaların 1967-2017 eğitim tahminleri

Şekil 11'de de görüldüğü gibi lineer olmayan değişimi LSTM, Poisson regresyonu ve ANFIS daha iyi modelleyebilmektedir. 1967-2017 y1lları ile eğitilen modellerin 2018-2031 yıllarına ait tahminleri ise Tablo 14'te görülmektedir. 
Tablo 14. En uygun parametrelere sahip yöntemlerin 20182031 tahminleri

\begin{tabular}{|c|c|c|c|c|c|}
\hline $\begin{array}{c}\text { Y11/Yönte } \\
\mathrm{m}\end{array}$ & $\begin{array}{c}\text { ANFI } \\
\mathrm{S}\end{array}$ & LR & YSA & $\begin{array}{c}\text { LST } \\
\mathrm{M}\end{array}$ & $\begin{array}{c}\text { Poisso } \\
\mathrm{n}\end{array}$ \\
\hline 2018 & 9.71 & 8.00 & 7.98 & 9.91 & 10.83 \\
\hline 2019 & 10.09 & 8.17 & 8.14 & 10.32 & 11.45 \\
\hline 2020 & 10.47 & 8.34 & 8.31 & 10.74 & 12.10 \\
\hline 2021 & 10.86 & 8.52 & 8.48 & 11.16 & 12.79 \\
\hline 2022 & 11.26 & 8.69 & 8.64 & 11.59 & 13.52 \\
\hline 2023 & 11.65 & 8.86 & 8.81 & 12.03 & 14.29 \\
\hline 2024 & 12.05 & 9.03 & 8.97 & 12.47 & 15.10 \\
\hline 2025 & 12.45 & 9.21 & 9.14 & 12.91 & 15.96 \\
\hline 2026 & 12.86 & 9.38 & 9.30 & 13.36 & 16.87 \\
\hline 2027 & 13.26 & 9.55 & 9.47 & 13.82 & 17.83 \\
\hline 2028 & 13.67 & 9.72 & 9.64 & 14.27 & 18.84 \\
\hline 2029 & 14.07 & 9.90 & 9.80 & 14.73 & 19.91 \\
\hline 2030 & 14.48 & 10.0 & 9.97 & 15.20 & 21.04 \\
\hline 2031 & 14.88 & $\begin{array}{c}7 \\
4\end{array}$ & 10.1 & 15.67 & 22.24 \\
\hline
\end{tabular}

Tablo 14'te de görüldüğü gibi genel bir artıș söz konusu olup LSTM'nin 2031 y1lı için öngördüğü 15.67 milyar tonluk sera gazı emisyonu en olası tahmin olarak düşünülmektedir. Tablo 14'te yer alan 2018-2031 y1llarına ait sera gazı emisyonu tahminleri Şekil 12'de görülmektedir.

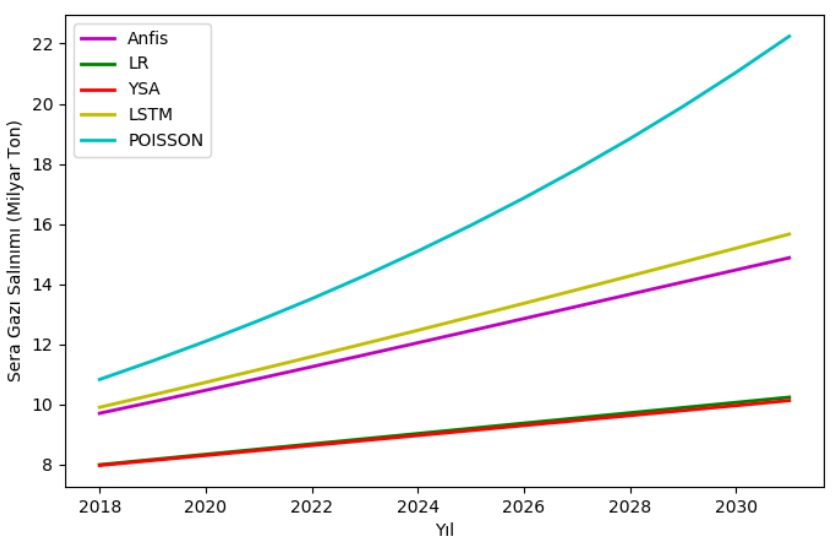

Şekil 12. Algoritmaların 2018-2031 tahminleri

Şekil 12'de de görüldüğü gibi tüm yöntemler belli bir artış öngörse de LSTM ve ANFIS yöntemlerinin öngördükleri yaklaşık 15 milyar tonluk sera gazı emisyonu tahminleri günümüze göre yüksek seviyede olup bu değerler göz önüne alınarak gerekli biyokütle artırıcı faaliyetlerin gerçekleştirilmesi gerekmektedir. Gelecekte alınacak tedbirler açısından modellerin ortaya koydukları tahmin değerleri büyük önem arz etmektedir.

\section{SONUÇ}

Dünyamız nüfustaki hızlı artışa ek olarak doğaya zararlı kimyasal ürünler ve genel tüketimdeki artış sebebiyle kendini yenileme konusunda artık insanlara yetmemektedir. Öyle ki bu durum şu an kaç adet Dünya'ya ihtiyacımız olduğu konusunda da çeşitli çalışmalarda görülmektedir. Tüketimlere bağlı olarak dünyamızın ekolojik ayak izi artmakta, bunun en büyük sebeplerinden biri de sera gazı emisyonundaki artış olarak görülmektedir. Dünyanın yenilenebilir olarak üretebildiği kaynaklar olan biyokütle miktarının ekolojik ayak izi ile dengede olması gerekmekte olup, bu denge ekolojik ayak izi tarafına doğru artan eğilim olduğunda dünya için olumsuz şartlar oluşmaktadır. Bu olumsuzluklar arasında ozon tabakasının delinmesi, küresel ısınma ve doğal kaynakların yetmemesi gibi durumlar bulunmaktadır. Bu olumsuzlukların yaşanmaması için gerek dünya genelinde gerekse ülkeler bazında daha yaşanılabilir ve kendi kendine yetebilen bir dünya için sera gazı emisyonunun durumu incelenmeli ve tedbirler alınmalıdır. Bunu gerçekleştirmek için de ileriye yönelik sera gazı emisyonunun öngörülmesi gerekmektedir.

$\mathrm{Bu}$ çalışmada gerçekleştirilen Türkiye'nin sera gazı emisyonu modellemesi ve tahmini de Türkiye açısından ileriye yönelik tedbirler alınması açısından faydalı olacaktır. İlgili makine öğrenimi algoritmaları zaman serisi ve 10-kat çapraz doğrulama ile test edilmiştir. LSTM, ANFIS, Poisson regresyonu, YSA ve LR algoritmalarının zaman serisi ve 10kat çapraz doğrulama ile test edilmesi sonucunda en iyi sonuç veren yöntem olarak LSTM tespit edilmiştir. LSTM'nin normalize edilmiș veride 45 nöron ve 0.05 Öo ile test seti için elde ettiği RMSE, MAPE ve $\mathrm{R}^{2}$ değerleri sırası ile $0.25,1.11,1.0$ olarak bulunurken, bu değerlere ait Wilcoxon Rank Sum testi için null test kabul edilip $p$ değeri olarak 1.0 elde edilmiştir. Aynı parametreler ile LSTM'nin çapraz doğrulama sonucunda elde ettiği RMSE, MAPE ve $\mathrm{R}^{2}$ değerleri ise sırası ile 0.02, 0.75, 1.0 olarak bulunurken, bu değerlere ait Wilcoxon Rank Sum testi için null test kabul edilip $p$ değeri olarak 0.99 elde edilmiştir. Bu başarılı sonuçlar ile oluşturulan model 2018-2031 yılına kadar olan sera gazı emisyonunu tahmin etmek için kullanılmıştır. İleriye yönelik tahmin değerleri incelendiğinde ise 2031 y1lı için tüm algoritmalar artış öngörürken, en başarılı bulunan LSTM 15.67 milyar ton olarak sera gazı emisyonunu hesaplamıştır. Bu değerler gerek Türkiye için gerekse dünya açısından tehlikeli ve yüksek olup, tahmin edilen değerler dikkate alınıp sera gazını önleyici veya biyokütleyi artırıcı tedbirlerin alınması gerekmektedir. İleriki çalışmalarda sera gazı emisyonlarının da etkisinin olduğu ekolojik ayak izi değeri ile dünyamıza ait biyokütleyi dengelemek için biyokütleyi artırıcı yönde faaliyetlerin optimizasyonu üzerine çalışılabilir. 


\section{KAYNAKÇA}

[1]. H. Ritchie and M. Roser, URL: https://ourworldindata.org/co2-and-other-greenhouse-gasemissions (Erişim zamanı; Eylül, 1, 2019).

[2]. S. Kalra, R. Lamba and M. Sharma, "Machine learning based analysis for relation between global temperature and concentrations of greenhouse gases.", Journal of Information and Optimization Sciences, vol. 41, no 1, pp. 73-84, 2020.

[3]. N. Li, L. Shang, Z. Yu and Y. Jiang, "Estimation of agricultural greenhouse gases emission in interprovincial regions of China during 1996-2014.", Natural Hazards, pp. 1-22, 2020.

[4]. A. J. Franzluebbers, Cattle grazing effects on the environment: Greenhouse gas emissions and carbon footprint, In Management Strategies for Sustainable Cattle Production in Southern Pastures, Academic Press, pp. 11-34, 2020.

[5]. M. Han and B. Zhu, B. "Changes in soil greenhouse gas fluxes by land use change from primary forest.", Global Change Biology, vol. 26, pp. 2656-2667, 2020.

[6]. S. Chicherin, "Low-Temperature District Heating With Decentralized Generation By Heat Pumps At A Railway Station: Optimizing The System And Calculating Greenhouse Gas Emissions," Innovations, vol.6, no 2, pp. 82-84, 2018.

[7]. H. Chen, M. K. Awasthi, T. Liu, J. Zhao, X. Ren, M. Wang, Y. Duan, S. K. Awasthi and Z. Zhang, "Influence Of Clay As Additive On Greenhouse Gases Emission And Maturity Evaluation During Chicken Manure Composting.", Bioresource technology, vol. 266, pp. 82-88, 2018.

[8]. H. Gülhan, H. Özgün, M. E. Erşahin, R. K. Dereli and İ. Öztürk, “İstanbul'daki Biyolojik Atıksu Arıtma Tesislerinin Sera Gazı Emisyonunun Modelleme Metodu ile Tahmini,”, Frrat Üniversitesi Mühendislik Bilimleri Dergisi, vol. 30, no 1, pp. 59-67, 2018.

[9]. T. A. Räsänen, O. Varis, L. Scherer and M. Kummu, "Greenhouse Gas Emissions Of Hydropower In The Mekong River Basin.”, Environmental Research Letters, vol. 13, no 3, 034030, 2018.

[10]. M. F. Baran, H. A. Karaağaç, D. Mart, A. Bolat, and Ö. Eren, "Nohut Üretiminde Enerji Kullanım Etkinliği Ve Sera Gazı (Ghg) Emisyonunun Belirlenmesi (Adana Ili Örneği).", Avrupa Bilim Ve Teknoloji Dergisi, vol. 16, pp. 41-50, 2019. [11]. H. Dulkadiroğlu, “Türkiye'de Elektrik Üretiminin Sera Gazi Emisyonlari Açisindan İncelenmesi.”, Ömer Halisdemir Üniversitesi Mühendislik Bilimleri Dergisi, vol. 7, no 1, pp. 67-74, 2018.

[12]. B. Henderson, A. Golub, D. Pambudi, T. Hertel, C. Godde, M. Herrero, O. Cacho, and P. Gerber, "The Power And Pain Of Market-Based Carbon Policies: A Global Application To Greenhouse Gases From Ruminant Livestock Production.", Mitigation And Adaptation Strategies For Global Change, vol. 23, no 3, pp. 349-369, 2018.

[13]. Orhan, Ayşe Ebru, "Çimento Üretiminden Kaynaklanan Sera Gazı Emisyonlarının Hesaplanması”,
Yükseklisans Tezi, Hacettepe Üniversitesi Fen Bilimleri Enstitüsü, Ankara/Türkiye, 2018.

[14]. Tokay, Zeynep, "Türkiye'nin Çeltik Yetiştiriciliği Kaynaklı Sera Gazı Emisyonlarının Değerlendirilmesi”, Yükseklisans Tezi, Hacettepe Üniversitesi Fen Bilimleri Enstitüsü, Ankara/Türkiye, 2018.

[15]. Z. Zhang, H. Li, H. Chang, Z. Pan and X. Luo, "Machine Learning Predictive Framework For $\mathrm{Co}^{2}$ Thermodynamic Properties In Solution.”, Journal Of Co2 Utilization, vol. 26, pp. 152-159, 2018.

[16]. I. Sefiner, "Some Artificial Neural Network Applications To Greenhouse Environmental Control,", Computers And Electronics In Agriculture, vol. 18 no 2-3, pp. 167-186, 1997.

[17]. H. Kargupta, J. Gama and W. Fan, "The Next Generation Of Transportation Systems, Greenhouse Emissions, And Data Mining", In Proceedings Of The 16th Acm Sigkdd International Conference On Knowledge Discovery And Data Mining, Acm, 1209-1212, (2010).

[18]. A. Nabavi-Pelesaraei, R. Abdi, S. Rafiee, S. Shamshirband and M. Yousefinejad-Ostadkelayeh, "Resource Management In Cropping Systems Using Artificial Intelligence Techniques: A Case Study Of Orange Orchards In North Of Iran.", Stochastic Environmental Research And Risk Assessment, vol. 30, no 1, pp. 413-427, 2016.

[19]. T. B. Nguyen, W. Schoepp and F. Wagner, "Gains-Bi: Business Intelligent Approach For Greenhouse Gas And Air Pollution Interactions And Synergies Information System,", In Proceedings Of The 10th International Conference On Information Integration And Web-Based Applications \& Services, Acm, 332-338, (2008).

[20]. K. A. Nguyen, O. Sahin, R. A. Stewart, and H. Zhang, "Smart Technologies In Reducing Carbon Emission: Artificial Intelligence And Smart Water Meter,", In Proceedings Of The 9th International Conference On Machine Learning And Computing, Acm, 517-522, (2017).

[21]. T. B. Nguyen, F. Wagner and W. Schoepp, "Cloud Intelligent Services For Calculating Emissions And Costs Of Air Pollutants And Greenhouse Gases,", In Asian Conference On Intelligent Information And Database Systems Springer, Berlin, Heidelberg, 159-168, (2011).

[22]. M. A. Behrang, E. Assareh, M. R. Assari and A. Ghanbarzadeh, "Using Bees Algorithm And Artificial Neural Network To Forecast World Carbon Dioxide Emission.", Energy Sources, Part A: Recovery, Utilization, And Environmental Effects, vol. 33, no 19, pp. 1747-1759, 2011.

[23]. A. Nabavi-Pelesaraei, S. Rafiee, S. S. Mohtasebi, H. Hosseinzadeh-Bandbafha and K. W. Chau, "Integration Of Artificial Intelligence Methods And Life Cycle Assessment To Predict Energy Output And Environmental Impacts Of Paddy Production.", Science Of The Total Environment, vol. 631, pp. 1279-1294, 2018.

[24]. H. Hosseinzadeh-Bandbafha, A. Nabavi-Pelesaraei and S. Shamshirband, "Investigations Of Energy Consumption And Greenhouse Gas Emissions Of Fattening Farms Using Artificial Intelligence Methods.”, Environmental Progress \& Sustainable Energy, vol. 36, no 5, pp. 1546-1559, 2017. 
[25]. N. Pillai, S. L. Schwartz, T. Ho, A. Dokoumetzidis, R. Bies and I. Freedman, "Estimating parameters of nonlinear dynamic systems in pharmacology using chaos synchronization and grid search.", Journal of Pharmacokinetics and Pharmacodynamics, vol. 46, no 2, pp. 193-210, 2019.

[26]. Ncss Statistical System Software User's Guide. URL: Https://Www.Ncss.Com/Software/Ncss/Ncss-

Documentation/ (Erişim zamanı; Eylül, 8, 2019).

[27]. A. C. Cameron and P. K. Trivedi, Regression Analysis Of Count Data. New York: Cambridge University Press, Ny, 1998.

[28]. I. Goodfellow, Y. Bengio and A. Courville, Deep Learning. Cambridge, Ma: Mit Press, 2016.

[29]. J. S. R. Jang, “ANFIS Adaptive-Network-Based Fuzzy Inference Systems.”, Man, And Cybernetics, vol. 23, no 3, pp. 665-685, 1993.

[30]. S. Hochreiter and J. Schmidhuber, "Long short-term memory.", Neural computation, vol. 9, no 8, pp. 1735-1780, 1997.

[31]. G. Işık and H. Artuner, "Uzun kısa-dönem bellekli sinir ağlarıyla prozodik açıdan türkçe ağız tanıma.”, Gazi Üniversitesi Mühendislik Mimarlık Fakültesi Dergisi, vol. 35, no 1, 213-224, 2020.

[32]. X. Wang, F. Zhang, H. T. Kung, V. C. Johnson and A. Latif, "Extracting soil salinization information with a fractional-order filtering algorithm and grid-search support vector machine (GS-SVM) model.”, International Journal of Remote Sensing, vol. 41, no 3, pp. 953-973, 2020.

[33]. I. Goodfellow, Y. Bengio and A. Courville, Derin Öğrenme. Buzdağı Yayınevi, Ankara, 2016. 